\title{
Caracterización del trabajo decente en Medellín y otras ciudades principales de Colombia (2010-2018)*
}

\author{
Silvio Fernando López Mera**
}

Fecha de recepción: 15 de agosto de 2019

Fecha de aprobación: 2 de diciembre de 2019

Resumen: En la última década del siglo XX, la Organización Internacional del Trabajo (OIT), teniendo en cuenta las transformaciones, problemáticas, nuevas relaciones y dinámicas que ocurrían en el empleo, propuso una concepción novedosa sobre este: el trabajo decente. A partir de la Gran Encuesta Integrada de Hogares (GEIH) del DANE de 2010-2018, de la base RLDatos de riesgos laborales de la Federación de Aseguradores Colombianos (Fasecolda) y del Sistema de Información Sindical y Laboral (Sislab) de la Escuela Nacional Sindical (ENS), el estudio estima el empleo para el agregado nacional, Medellín y otras ciudades principales del país, y una serie de indicadores en el marco de las dimensiones del trabajo decente. Si bien es cierto que según los resultados el país ha avanzado en materia de empleo digno, este ha sido insuficiente. Por lo que todavía falta camino para poder afirmar que el empleo en Colombia es decente. Así mismo, se evidencian diferencias importantes entre territorios.

Palabras clave: trabajo decente, economía laboral, empleo, GEIH, Medellín.

Clasificación JEL: J08, J30, J60, J70, J81, J88.

Cómo citar este artículo/ To reference this article / Comment citer cet article / Para citar este artigo:

López Mera, S. (2020). Caracterización del trabajo decente en Medellín y otras ciudades principales de Colombia (2010-2018). Apuntes Del Cenes, 39(69). Págs. 169 - 217. https://doi.org/10.19053/01203053.v39.n69.2020.9915

\footnotetext{
Estudio inspirado en la participación del autor como miembro del Comité Técnico del Observatorio Regional de Mercado de Trabajo (ORMET) de Antioquia y en investigaciones anteriores sobre trabajo decente.

** Economista. Magíster en Políticas Públicas y en Economía. Docente investigador Universidad EAFIT y Universidad Autónoma Latinoamericana. Colombia. Correo electrónico: silvio.lopez@medellin.gov.co Q. https://orcid.org/0000-0002-7577-0881
} 


\title{
Characterization of Decent Work in Medellin and other Main Cities of Colombia (2010-2018)
}

\begin{abstract}
International Labor Organization (ILO), taking into account the transformations, problems, new relationships and dynamics that occurred in employment, proposed in the last decade of the $20^{\text {th }}$ century a novel concept on employment: decent work. Based on the 2010-2018 Great Integrated Household Survey (GEIH by its acronym in Spanish) of the National Administrative Department of Statistics (DANE, by its acronym in Spanish), the base RLDatos of occupational risks of Fasecolda and the Sislab of Escuela Nacional Sindical (ENS), this paper estimates the employment for the national added value, for Medellin and other important cities of the country, and a series of labor indicators within the framework of the dimensions of decent work proposed by the ILO. The results indicate that, although the country has made progress in terms of decent employment, it has been insufficient, so there is still a long way to conceive employment in Colombia as decent. In the same way, important differences between territories are evident.
\end{abstract}

Keywords: decent work, labor economics, employment, GEIH, Medellin. 


\section{INTRODUCCIÓN}

Desde el año 1999, la Organización Internacional del Trabajo (OIT) viene promoviendo la implementación de políticas que permitan crear las condiciones necesarias y suficientes para la generación de empleos decentes en las naciones -especialmente en las más pobres, con importante explotación laboral y desigualdad-, así como instrucciones de medición del trabajo decente.

Esta nueva concepción del empleo -que surge debido a la precarización que ha sufrido el trabajo, así como a las trasformaciones de este a causa de la globalización, competitividad e integración económica y flexibilización de las relaciones laborales-, no solo considera la importancia de crear suficientes puestos de trabajo para responder a la presión demográfica y a las necesidades de las sociedades, sino también la importancia de que estos sean empleos productivos y de calidad, sustentados en condiciones de libertad, igualdad y seguridad, que dignifiquen al ser humano en un mundo globalizado con nuevos desafíos socioeconómicos y comerciales.
El presente artículo es pionero en el país en estudiar y hacer comparativos del trabajo decente en varios entes territoriales de la nación y para un periodo extenso, a fin de determinar qué tan distante se encuentra Colombia de esta concepción del empleo, lo que permite tener una visión general y espacial de la realidad y los desafíos en materia de trabajo decente en el país, asunto clave en el marco de los Objetivos de Desarrollo Sostenible (ODS). Aquí se caracteriza el empleo para el periodo 2010-2018 para el agregado nacional, Medellín y su área metropolitana y otras ciudades capitales (Barranquilla, Bogotá, Bucaramanga, Cali, Cúcuta y Manizales), así como el departamento de Antioquia, con el objetivo de identificar la realidad, los avances, las oportunidades y los retos del país en materia de trabajo decente y hacer visibles las importantes diferencias que muestran los resultados en el ámbito de territorios.

Para ello se emplean los microdatos de la Gran Encuesta Integrada de Hogares (GEIH) del Departamento Administrativo Nacional de Estadística (DANE), 
las estadísticas de la fuente de riesgos laborales (RLData) de la Federación de Aseguradores Colombianos (Fasecolda) y el Sistema de Información Laboral y Sindical (Sislab) de la Escuela Nacional Sindical (ENS). Con estas fuentes se construyó un conjunto de indicadores inspirados y adaptados de la OIT.

Para lograr el objetivo, el documento se divide en cuatro secciones, aparte de esta introducción. La primera detalla el origen, la conceptualización y las características de lo que se conoce como trabajo decente, así como las dimensiones que lo cubren según la OIT. La siguiente detalla los datos y la metodología empleada. La tercera sección reporta el conjunto de indicadores para las unidades geográficas de interés distribuido en las dimensiones junto con una serie de recomendaciones de política pública a la luz de los resultados y principales hallazgos. En el último capítulo, a manera de conclusión, se menciona que las diferencias entre los territorios son evidentes, pues existen brechas en términos de trabajo decente, lo que nos lleva a afirmar que el país tiene un camino suficientemente largo por recorrer antes de poder considerar a su mundo laboral como decente. En definitiva, es importante apuntarle a los Objetivos de Desarrollo Sostenible de manera contundente.

\section{TRABAJO DECENTE: GÉNESIS, DEFINICIÓN Y DESCRIPCIÓN}

El trabajo decente se define como aquella ocupación productiva justamente remunerada y ejercida en condiciones de libertad, equidad, seguridad y respeto por la dignidad humana (OIT, 1999) ${ }^{1}$. Parte de la coexistencia de cuatro condiciones que el empleo debería tener para ser denominado como decente. Estos cuatro elementos u objetivos que deberían trazarse los hacedores de política laboral para convertir los mercados de trabajo en decentes, son los siguientes (ver Figura 1):

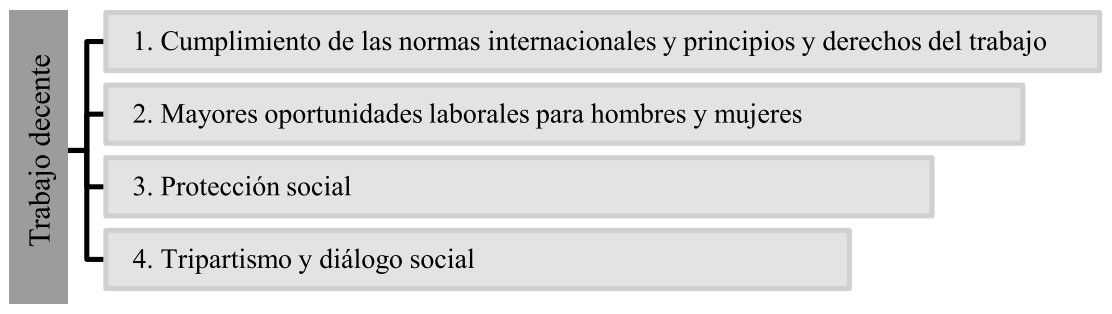

Figura 1. Pilares del trabajo decente.

Fuente: OIT (2008).

1 Una reflexión detallada del concepto trabajo decente y su diferencia con trabajo digno o empleo de calidad puede encontrarse en Pineda (2013). 
El primer elemento lleva a que los empleadores respeten las normas, principios y derechos fundamentales del trabajo, de tal forma que en el mundo laboral los ciudadanos se puedan desarrollar libremente y los trabajadores en situación de vulnerabilidad tengan representación. El segundo se refiere a que los gobiernos deben generar las condiciones para que los sectores económicos estén en la capacidad de crear vacantes, oportunidades de inversión, iniciativas empresariales y cualificaciones de sus ciudadanos. El tercer elemento se relaciona con proteger a los trabajadores, a los buscadores y a los incapacitados para trabajar. Y el último busca que las naciones fortalezcan la triada (Gobierno-Empresarios-
Trabajadores) para mayor diálogo y cohesión social.

Para la medición práctica del trabajo decente, la OIT (ILO por sus siglas en inglés) estableció once dimensiones ${ }^{2}$ que se relacionan con los cuatro pilares, conformada cada una por una serie de indicadores medibles y comparables que permitan concluir sobre la situación y retos frente al trabajo decente. Estas dimensiones determinantes para el diseño de políticas y programas, tanto de empleo como económicas y sociales, se indican, junto con el número de indicadores definidos por la ILO (2012) y los priorizados en este estudio por interés y disponibilidad de la información e interés, en la Tabla 1.

Tabla 1. Dimensiones ${ }^{3}$ y sus indicadores

\begin{tabular}{lc}
\hline \multicolumn{1}{c|}{ Descripción } & $\begin{array}{c}\mathrm{N} .^{\circ} \text { Indicadores } \\
\text { definidos por OIT } \\
\text { / N. } .^{\circ} \text { Indicadores } \\
\text { estimados }\end{array}$ \\
\hline 1. Oportunidades de empleo (1 y 2) & $11 / 11$ \\
\hline Recoge el desempeño y evolución del mercado laboral entendido como la capacidad que tiene para
\end{tabular}
absorber la oferta de trabajo mediante la disponibilidad de empleos dignos y estables. Esta dimensión es una condición necesaria para comprender la concepción del trabajo decente, pero resulta insuficiente para determinar cuándo una economía cuenta realmente con empleos decentes, porque no permite realizar un análisis sobre la calidad de las empleos y vacantes. La existencia de otras dimensiones recalca el hecho de que el trabajo decente no es solo cuestión de cantidad. En síntesis, esta es la dimensión básica cuando se caracteriza el empleo.

2. Ingresos adecuados y trabajo productivo (1 y 3 ) $7 / 5$

El trabajo remunerado es la principal fuente de ingresos de los hogares, por lo que un trabajo decente implica necesariamente la remuneración suficiente a los trabajadores, bajo consideraciones mínimas que permitan suplir aquellos mínimos vitales y acceder y mantener una vida digna.

$\overline{2}$ La dimensión 11 no se aborda en este estudio por contener indicadores macroeconómicos que abundan en la literatura.

3 Entre paréntesis se identifica a cuáles de los cuatro pilares pertenece o se relaciona cada dimensión. 
La dimensión recoge la necesidad de que los puestos de trabajo se adapten a la legislación laboral de cada país con respecto al número máximo de horas de trabajo y la situación de los trabajadores de acuerdo con sus necesidades. La dimensión destaca la importancia de los acuerdos entre empleado y su empleador y el tiempo del trabajador para otros fines.

\section{Conciliación del trabajo, la vida familiar y la vida personal (1 y 3) \\ $2 / 1$ \\ Esta dimensión considera que los trabajadores tienen una vida más allá de su empleo y que, por tanto, para su dignificación y desarrollo humano requieren contar con una vida personal y familiar.}

5. Trabajo que debería ser abolido (1 y 3)

De acuerdo con la máxima autoridad laboral en el mundo, el trabajo infantil y el trabajo forzoso deberían abolirse. El primero, porque le impide al niño(a) la posibilidad de escolarizarse y de desarrollarse plenamente en libertad sin ningún trastorno. El segundo porque atenta contra la integridad física, mental o moral del trabajador. La medición del trabajo que debería abolirse es necesaria para poder determinar sus características e incidencia y así diseñar políticas de erradicación.

\section{Estabilidad y seguridad del trabajo $(1,2,3)$}

$4 / 2$

Recoge la preocupación de la inestabilidad, poca duración y falta de seguridad social de los empleos que se crean en los mercados de trabajo. Las características de los contratos de trabajo son consideradas en esta dimensión, en términos de duración, tipo de contratante, cubrimiento.

\section{Igualdad de oportunidades y trato en el empleo $(1,2,3) \quad 8 / 2$}

El trabajo decente implica la existencia de igualdad de oportunidades y trato, sin ningún tipo de discriminación o segregación; sin embargo, la evidencia indica la discriminación laboral por orientación sexual, creencia religiosa, etnia, procedencia, afiliación política, entre otras. La dimensión se centra en hacer evidente la discriminación que persiste en los mercados de trabajo en contra de las mujeres.
8. Entorno de trabajo seguro (1 y 3)
$4 / 3$
Esta dimensión indica que la seguridad y la salud en el trabajo son componentes vitales del trabajo decente. De acuerdo con la OIT, el "trabajo decente en un trabajo seguro". La información que se recopile en esta dimensión es determinante para el diseño de políticas y programas de prevención de accidentes laborales y priorización de intervención en aquellos sectores o actividades económicas donde más se producen accidentes o donde hay más riesgo laboral.

\section{\begin{tabular}{ll}
\hline 9. Seguridad social (1 y 3) & $10 / 2$
\end{tabular}}

En el marco del trabajo, la seguridad social cubre al trabajador de todos los riesgos que puede vivir en su ocupación (falta de ingresos por enfermedad, invalidez, maternidad, accidentes de trabajo, desempleo, vejez o muerte de un familiar; dificultad para acceder a atención médica; falta de apoyo familiar; pobreza y exclusión social). Bajo la concepción del trabajo decente, el acceso a un nivel adecuado de protección social es un instrumento para la promoción del bienestar humano y el consenso social, que favorece la paz social y es indispensable para lograrla y, por lo tanto, para mejorar el crecimiento equitativo, la estabilidad social y el desempeño económico, contribuyendo a la competitividad.

\section{Diálogo social y representación de empleadores y trabajadores (1 y 4) 5/1}

Esta dimensión recoge la importancia de que entre gobierno, gremio de empleadores (y sus sindicatos) y trabajadores logren el diálogo social para promover trabajos en condiciones de libertad, igualdad, seguridad y dignidad humana. Entiéndase diálogo social como aquel que incluye todos los tipos de negociación, consulta e intercambio de información entre representantes de esta triada sobre temas de interés común. El principal objetivo del diálogo social es la promoción del consenso y democracia de los actores del mundo laboral.

$\begin{array}{ll}\text { Total } & 61 / 31\end{array}$

Fuente: el autor, con base en OIT (2001). 
Luego de debates e investigaciones desde 1999, la OIT en el 2008 avanzó en la definición inicial de 66 indicadores estadísticos y 20 jurídicos (estos últimos no considerados aquí) que brindan información de los cuatro pilares y las dimensiones que conforman la concepción del trabajo decente ${ }^{4}$. Posteriormente, en el 2012, fueron actualizados y se enfatizó en la necesidad de desagregarlos, según características de la población, para identificar diferencias (discriminación), especialmente por género.

\section{METODOLOGÍA Y DATOS}

Se estima una serie de indicadores distribuidos en las diez de las once dimensiones consideradas, lo cual da luces de la realidad y retos que tiene la nación y sus territorios en materia de trabajo decente. La metodología consiste en analizar cada indicador en el tiempo y entre unidades geográficas, acompañado en algunos casos de recomendaciones de política pública. En algunos casos se examinan promedios, en otros, tendencias o ampliación/reducción de brechas. En la Tabla A1.1 de Apéndices se reporta la ficha técnica de cada indicador, incluida la fórmula de cálculo.
En cuanto a la fuente, se emplea principalmente a través de Stata, los microdatos de la GEIH-DANE (2016) $)^{5}$ de los periodos 2010-2018 ${ }^{6}$. Se escoge 2010 como inicio del periodo de análisis, dado que desde este año y para las vigencias 2011 y 2014 a 2017, Medellín contó por primera vez con una encuesta de hogares exclusivamente para la ciudad, contratada con el DANE7 ${ }^{7}$. A efectos de comparación, los indicadores se estimaron para varias áreas/unidades geográficas. Teniendo en cuenta la representatividad estadística de la GEIH, las unidades geográficas de interés son:

- Medellín.

- Medellín y Área Metropolitana del Valle de Aburrá (que incluye los municipios de Caldas, La Estrella, Sabaneta, Itagüí, Envigado, Bello Copacabana y Barbosa, y que adelante es denotado como Medellín AMVA).

- El departamento de Antioquia.

- Barranquilla y Área Metropolitana (que incluye el municipio de Florida).

- Bogotá D.C.

- Bucaramanga y Área Metropolitana (que incluye los municipios de Floridablanca, Girón y Piedecuesta).

4 La OIT los presentó en la XVIII Conferencia Internacional de Estadísticos del Trabajo en diciembre de 2018 y los clasificó en principales, adicionales, de contexto y futuros, de acuerdo con la importancia, pertinencia y disponibilidad.

5 La GEIH (2016) proporciona información útil sobre el tamaño y la estructura de la fuerza de trabajo de la población del país en términos de empleo, desempleo e inactividad, entre otros. Además, permite caracterizar sociodemográficamente la población.

6 Pueden descargarse de: http://microdatos.dane.gov.co/index.php/catalog/MICRODATOS/about_collection/23/1

7 Anteriormente, la representatividad estadística de la GEIH era para Medellín y su Área Metropolitana. Desde esta década, se amplió la muestra para convertirla en representativa en la ciudad (y en sus 16 comunas). Medellín no cuenta con resultados representativos para los años 2012, 2013 y 2018, dado que para estos tres años la Alcaldía no contrató la GEIH adicional con el DANE. 
- Cali y Área Metropolitana (que incluye el municipio de Yumbo).

- Cúcuta y Área Metropolitana (que incluye los municipios de Villa del Rosario, Los Patios y El Zulia) ${ }^{8}$.

- Manizales y Área Metropolitana (que incluye el municipio de Villamaría).

- Nacional.

Para la dimensión 9 se empleó, además de la GEIH, la base de RLDatos de riesgos laborales de Fasecolda ${ }^{9}$, donde se reporta el número de empresas afiliadas, de trabajadores, accidentes, enfermedades y muertes calificadas en el trabajo, el promedio de trabajadores por empresa y las tasas de accidentes y muertes laborales. Para la dimensión 10 se usó el sistema Sislab de la $\mathrm{ENS}^{10}$, el cual contiene información del censo sindical, de la dinámica de la contratación colectiva y sindical, y otros indicadores laborales.

\section{TRABAJO DECENTE EN COLOMBIA}

Colombia recoge la preocupación de la OIT por los insuficientes empleos y la proliferación de trabajos precarios, y es así como a través de los planes nacionales, departamentales y municipales de desarrollo ha definido un abanico de estrategias que buscan alcanzar los ODS a 2030 en su dimensión "8 Trabajo Decente y Crecimiento Económico".
En el actual Plan Nacional de Desarrollo, por ejemplo, el país se ha trazado, entre otros, objetivos como el de aumentar los empleos formales, disminuir el desempleo en población vulnerable y aumentar el número de ciudadanos formados y certificados (Departamento Nacional de Planeación, 2019).

En el ámbito territorial, con el Decreto 1226 de 2009, la Alcaldía de Medellín creó el Consejo Municipal de Empleo y Productividad como un órgano tripartito $\mathrm{y}$ asesor en materia de empleo y al cual se le delegó la misión de construir la política de trabajo decente de la ciudad. Con el Acuerdo 064 de 2013, constituido por 11 artículos, se estableció la política pública de trabajo decente en Medellín. Posteriormente se publica el Plan Local de Empleo (Alcaldía de Medellín, 2017), reglamentación que impulsó el desarrollo de la primera medición de trabajo decente para la ciudad, liderada por el Observatorio de Mercado de Trabajo (ORMET) de Antioquia. Así mismo, motivó la inclusión de estrategias para el trabajo decente en el Plan Municipal de Desarrollo 2016-2019. Pero hasta el momento se desconoce el impacto de este tipo de iniciativas.

Bogotá, a través de su Secretaría de Planeación, viene elaborando la política pública de trabajo decente y digno, contemplada en el Decreto 380 de 2015.

\footnotetext{
8 Se incluye Cúcuta con el fin de identificar parte de la incidencia que tiene el fenómeno de la migración venezolana en la capital de Norte de Santander.

9 Ver datos en: https://sistemas.fasecolda.com/rldatos/reportes/xclasegrupoactividad.aspx

10 Ver datos en: http://www.ens.org.co/lee-y-aprende/lee-y-descarga-nuestras-publicaciones/informes-sislab/
} 
Mientras que el Valle del Cauca viene trabajando con la OIT los lineamientos para la construcción del proyecto de la política pública de trabajo decente y equidad laboral, con el "fin de promover la generación de empleo, la formalización y la protección social a través de acciones públicas y privadas articuladas para garantizar los derechos de los vallecaucanos" (Gobernación del Valle, 2019).

En cuanto a la medición, algunas entidades públicas y centros de investigación han adelantado estudios para medir el trabajo decente en el país (Observatorio del Mercado de Trabajo y la Seguridad Social, 2016; Procuraduría General de la Nación 2015; Pineda, 2013; Villamizar, 2011). Al igual que en estos estudios, aquí se realizan adaptaciones a los indicadores planteados por la OIT, en parte por la disponibilidad de la información para calcular el indicador y el particular contexto social, político y económico del país, con el fin de definir una batería de indicadores pertinentes y medibles que permita medir el avance en materia de trabajo decente del país y de varias de sus ciudades. A continuación se re- portan para las primeras diez dimensiones del trabajo decente, los principales indicadores estimados.

\section{Dimensión 1: oportunidades de empleo}

Esta dimensión contiene los indicadores tradicionales en economía laboral, como lo son la tasa de ocupación, desempleo e informalidad. Si bien estos son necesarios para analizar el trabajo decente, no son suficientes para determinar qué tan cerca o lejana se encuentra una economía de la concepción de trabajo decente, pues esta dimensión aborda principalmente la problemática de cantidades del empleo.

\section{Indicador 1.1 Tasa de ocupación}

Desde el 2016, la ocupación en el país y en varias ciudades se viene desacelerando después de seis años de continuo incremento. Mientras que en el 2015 la tasa de ocupación nacional se ubicó en el $59 \%$, tres años después esta cierra en el $57.8 \%$. (Figura 2) 


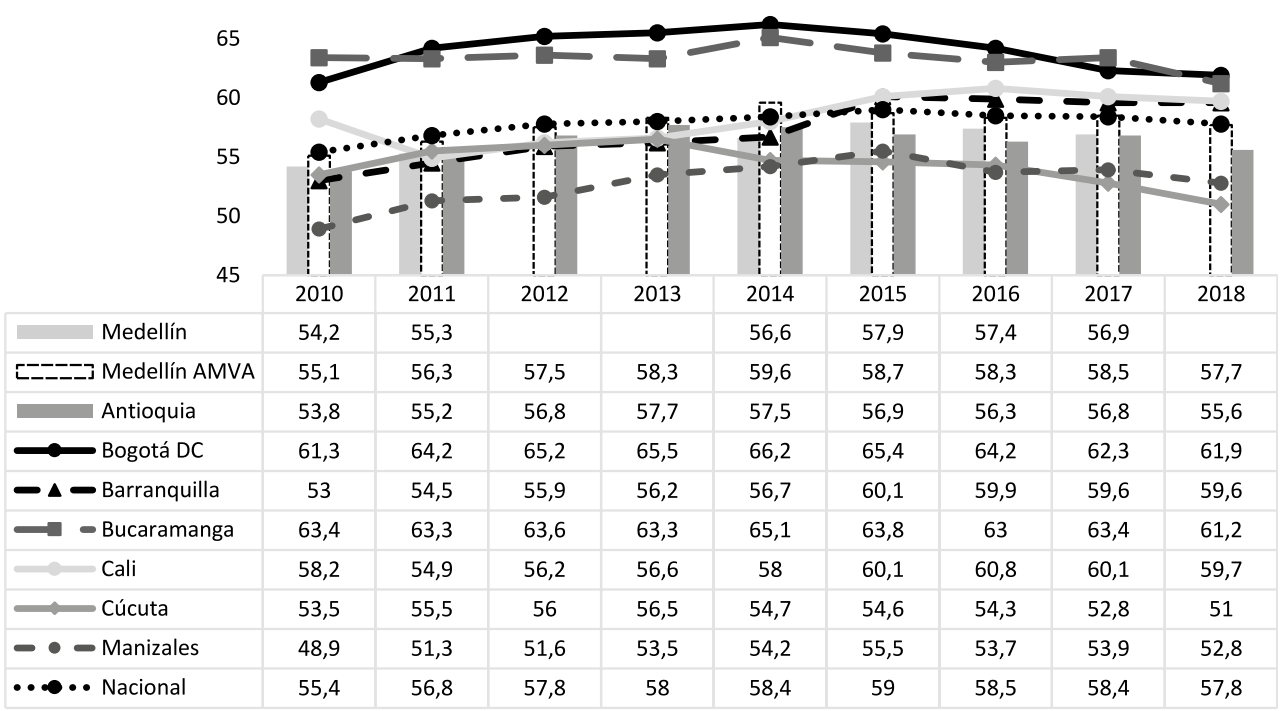

Figura 2. Tasa de ocupación para Medellín y otras ciudades: 2010-2018.

Fuente: el autor, con base en GEIH-DANE.

En las ciudades, la tasa de ocupación para Medellín en todo el periodo ha sido inferior a la registrada por Medellín AMVA, el agregado nacional, Bogotá, D.C. y Bucaramanga, y en la mayoría de los años, superior a la del departamento de Antioquia y los municipios de Manizales y Cúcuta. Esta desaceleración genera alarmas, porque con déficit de vacantes, el trabajo decente no puede predominar en la economía, pues como en cualquier mercado, un desequilibrio genera desventaja para un sector en particular (en este caso para la oferta).

\section{Indicador 1.2 Tasa de desempleo}

Aunque desde el 2013 el desempleo en el ámbito nacional es de un dígito (al igual que en Antioquia y Medellín y en toda la serie lo ha sido en Barranqui1la), este viene en ascenso desde hace cuatro años, lo que ratifica el problema mencionado de cantidades. La ciudad con mayor desempleo en el país de las analizadas es Cúcuta, que desde el 2011 ocupa el primer lugar y que es el primer municipio receptor y el más afectado por la migración de venezolanos (Campos, 2018). Medellín, en particular, tiene tasas más bajas que las registradas por Cali y Manizales, y al incluirse los otros municipios del Valle de Aburrá, la tasa exclusiva de Medellín es menor. Pero, sin duda, preocupa la pérdida de terreno con respecto al desempleo. Ahora, si se desagrega la desocupación por género y aunque no se muestra, la mayor tasa la reportan las mujeres (en 2018 fue 
de $12.7 \%$ vs. $7.4 \%$ para los hombres) -aunque ha disminuido más que la de los hombres-, situación constante en
Medellín y V.A., así como en el país. (Figura 3)

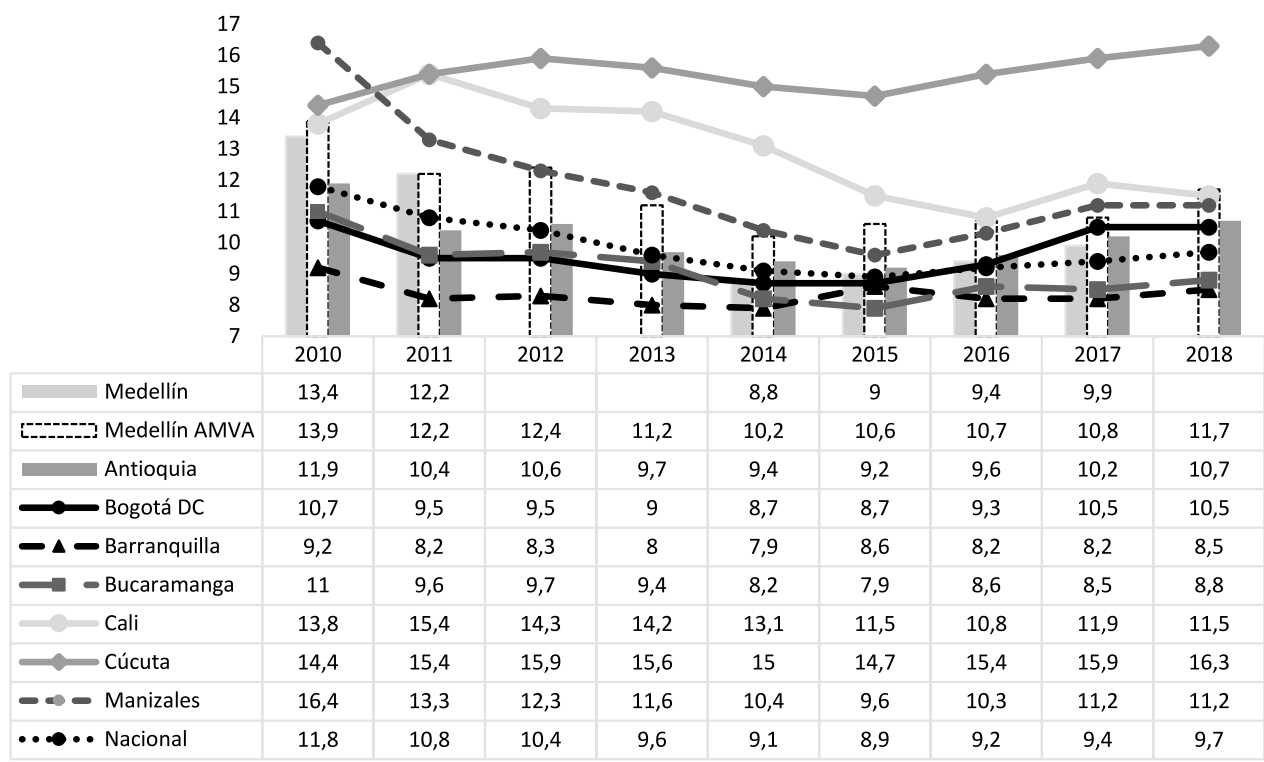

Figura 3. Tasa de desempleo para Medellín y otras ciudades: 2010-2018.

Fuente: el autor, con base en GEIH-DANE.

En este sentido, el país dejó de estar por el buen camino al pasar de registrar un comportamiento deseable a indeseable en los dos anteriores indicadores. El mecanismo más efectivo para frenar esta tendencia es a través de la creación y sostenibilidad de empresas generadoras de empleo formal; sin embargo, aquí hay un camino largo por recorrer, al menos para el caso particular de Medellín, por ejemplo, donde si bien la densidad empresarial -entendida como el número de empresas por cada mil habitantes-, ha venido en aumento desde el 2013, aún es insuficiente el emprendimiento (ver Figura 4).

En el país, las cifras igualmente indican que el stock de empresas formales va en aumento (Figura 5), y en la mayoría de los territorios de interés también. La política entonces se deberá centrar en promover un buen clima económico y facilitar los emprendimientos formales. 


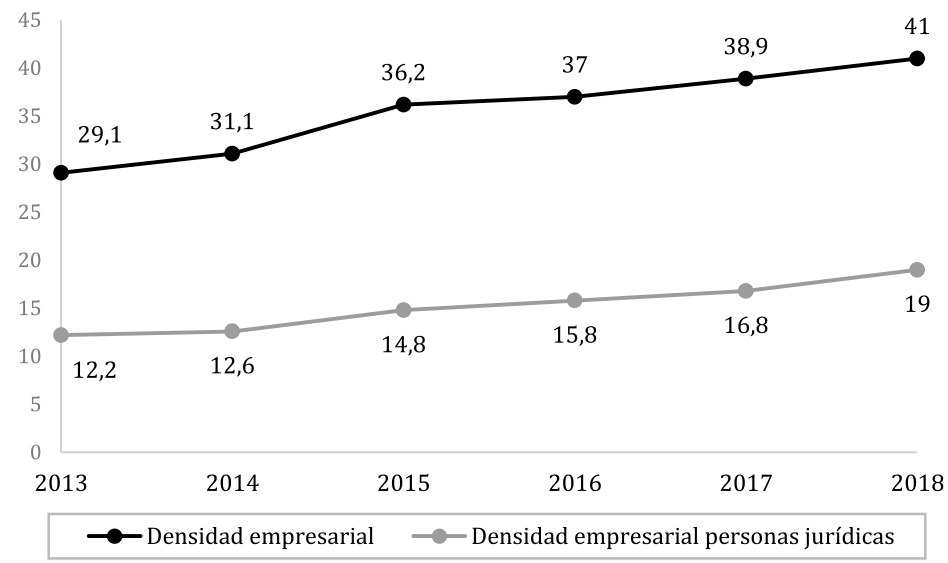

Figura 4. Densidad empresarial y de personas jurídicas para Medellín: 2013-2018.

Fuente: Cámara de Comercio de Medellín para Antioquia

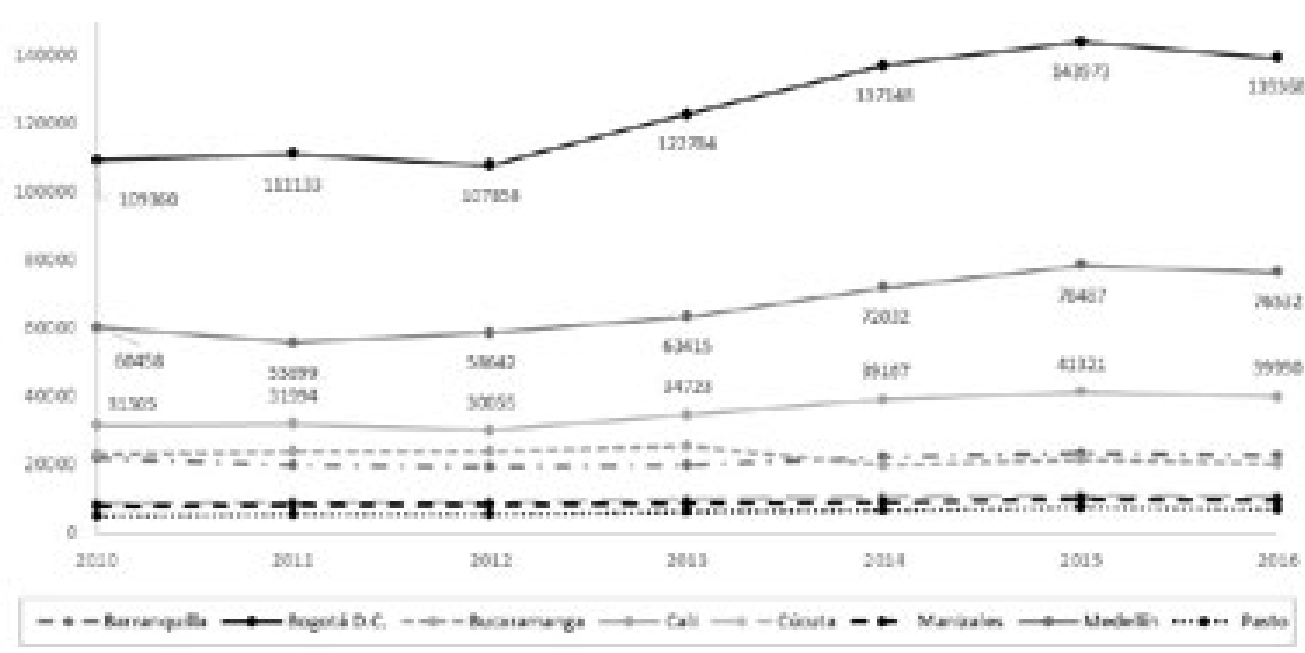

Figura 5. Número de empresas generadoras de empleo formal en Medellín y otras ciudades: 2010-2016.

Fuente: el autor, con base en FILCO (Mintrabajo).

Indicador 1.3 Tasa de NINI

Para medir problemáticas sociales en los jóvenes, la tasa de Nini (población que ni estudia ni trabaja) es útil. En general, desde el 2015 se viene presentando en el país un crecimiento de esta tasa (calculada para los jóvenes de 14 a 28 años), lo cual deja interrogantes tanto para el Ministerio de Educación como para el 
de Trabajo ${ }^{11}$. En toda la serie (Figura 6), Medellín solo es superado por Bogotá y Barranquilla, las cuales registran menores tasas. En particular, en el 2017 el $17.2 \%$ de los jóvenes no se encuentran ni trabajando ni estudiando en la capital de Antioquia, mientras que en el país esta tasa es del $20.8 \%$, la cual para el
2018 aumenta ligeramente a $21.7 \%$. La situación es más preocupante en Cúcuta y Barranquilla, donde son más los jóvenes quienes no se encuentran en alguna actividad productiva, situación que puede llegar a afectar, entre otros aspectos, la seguridad ciudadana.

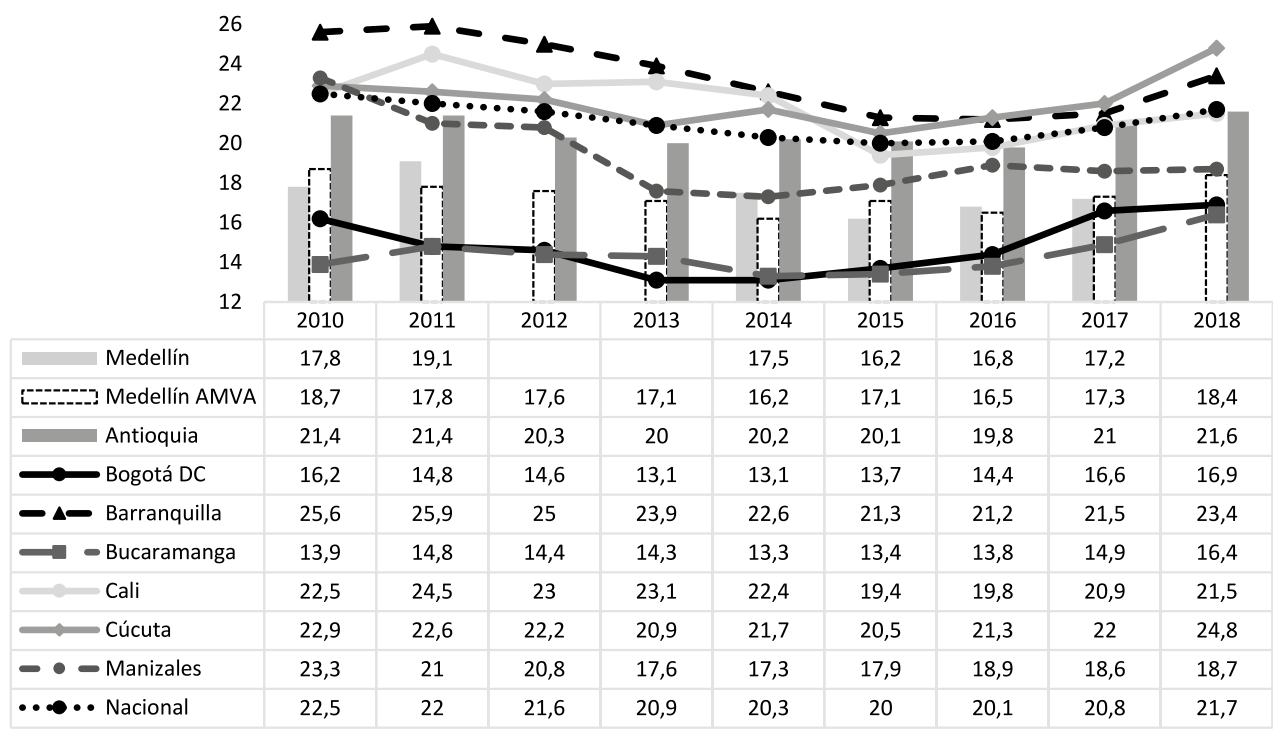

Figura 6. Tasa de NINI para Medellín y otras ciudades: 2010-2018.

Fuente: el autor, con base en GEIH-DANE.

En este orden de ideas, es importante generar políticas educativas y de empleo para los jóvenes y evitar así que terminen participando de actividades socialmente indeseables. En los territorios donde esta población ha disminuido, esto sugeriría que los jóvenes o están ingresando al mundo laboral o están accediendo a la educación. En aquellos casos donde se visualice una reducción de la tasa de desempleo juvenil (efecto visible en el país hasta el 2015) -indicador que más adelante se analiza-, se constataría que la juventud está siendo empleada. La reducción de Nini es un logro para el trabajo decente en la medida en que exista una inclusión laboral o educativa de los jóvenes, quienes históricamente

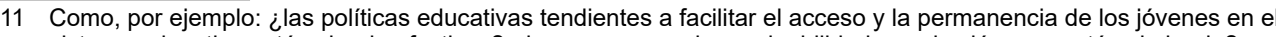
sistema educativo están siendo efectivas? ¿los programas de empleabilidad para los jóvenes están sirviendo? 
han sido una población vulnerable junto con las mujeres y minorías étnicas.

Indicador 1.4 Tasa de informalidad según tamaño de empresa Los anteriores indicadores dan cuenta de la problemática del empleo en términos de su cantidad. Y aquí vale enfatizar: si no hay empleo, no puede haber trabajo decente. Ahora bien, este y el siguiente indicador de informalidad dan cuenta adicionalmente de su calidad, y según las cifras, la informalidad está afectando prácticamente a la mitad de los ocupados. Es importante destacar aquí: informalidad implica trabajos no decentes.

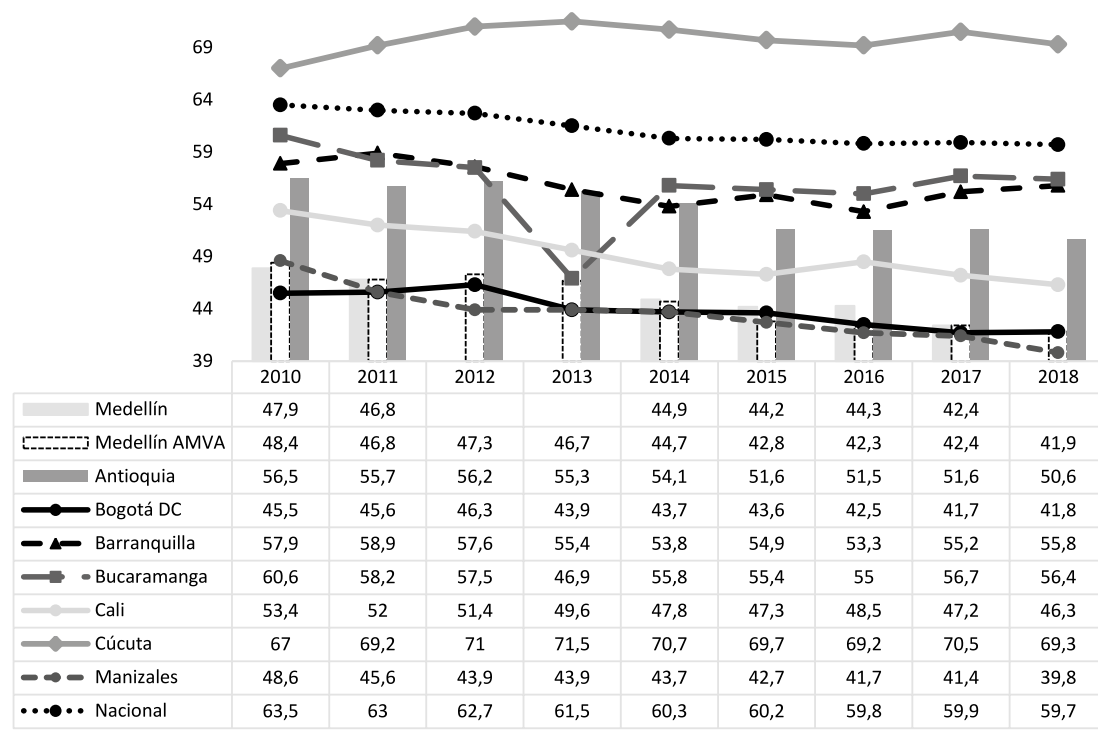

Figura 7. Tasa de informalidad según tamaño de empresa para Medellín y otras ciudades: 2010-2018.

Fuente: el autor, con base en GEIH-DANE.

En el país, en promedio, el $60 \%$ de los ocupados son informales ${ }^{12}$, mientras que la tasa de Bogotá es del $43.8 \%$ y la mínima del 41.8 \%. En Medellín, sin o con su área metropolitana, se registró en el 2017 una informalidad del 42.4\% (aunque con tendencia bajista), solo superada por Bogotá y Manizales, esta última la de menor tasa del país de las capitales consideradas. Cúcuta, por su parte, registra la mayor informalidad, incluso superior a la nacional: en promedio 7 de cada 10 ocupados son informales. (Figura 7)

\footnotetext{
12 Son informales aquellos empleados particulares y obreros que laboran en establecimientos, negocios o empresas que ocupen hasta cinco personas; los trabajadores familiares sin remuneración y otros perfiles. Para mayor información remitirse a: https://www.dane.gov.co/files/investigaciones/boletines/ech/ech_informalidad/bol_ech_informalidad_dic18_feb19.pdf.
} 
Indicador 1.5 Tasa de informalidad según afiliación a seguridad social (SS)

A diferencia del anterior, este indicador considera como informal al ocupado sin afiliación al sistema de salud y pensiones, situación indeseable dado que no le garantiza al trabajador cobertura por el Sistema de Seguridad Social en Salud ante cualquier enfermedad y recibir una pensión cuando este se encuentre en su etapa de vejez. En este sentido, un empleo sin esta cobertura no es decente, pues pone al trabajador y a su familia en una situación de vulnerabilidad. Nuevamente, Cúcuta registra la mayor informalidad del país (en promedio el $74 \%$ ), seguida por el agregado nacional (el cual viene cayendo de manera continua ubicándose en el 2018 en el $62.9 \%$ ) y por Barranquilla, que registró en el 2017 una informalidad del $62.9 \%$. Medellín, por su parte, viene registrando una tendencia a la baja de este indicador que en 2017 se ubicó en el $39.9 \%$, igual a la reportada cuando se incluye su área metropolitana. Entre 2016 y 2017, Manizales registra la menor informalidad del país $(40.3 \%$ y $38.6 \%$ ). (Figura 8 )

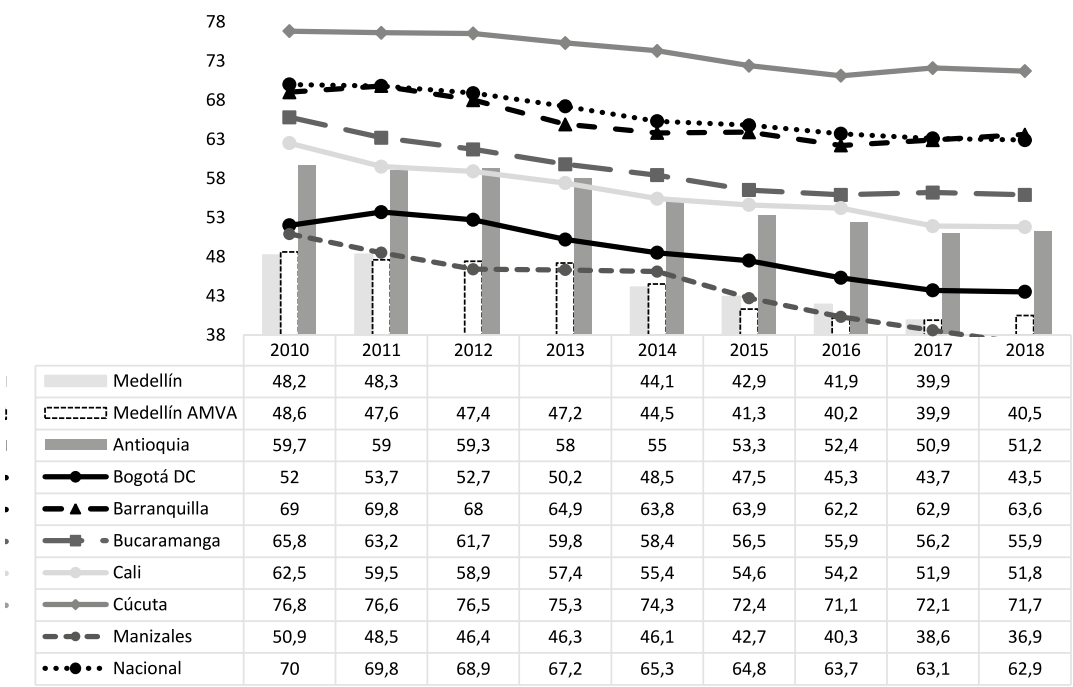

Figura 8. Tasa de informalidad según afiliación a SS para Medellín y otras ciudades: 2010-2018.

Fuente: el autor, con base en GEIH-DANE.

Independientemente de cuál de los dos indicadores de informalidad se considere, la problemática se mantiene latente en el país y se evidencian grandes diferencias entre territorios. Si gran parte de los empleos que se están generando en el país son informales, esto indicaría desde ahora, que en las dimensiones que faltan por abordar, el país no puede estar en un estado de cumplimiento, pues las 
características de la informalidad van en contravía de lo que se concibe como trabajo decente y repercuten en otras variables.

\section{Indicador 1.6 Tasa global de participa- ción (TGP)}

La TGP mide la presión que ejercen los movimientos naturales poblacionales sobre el mundo de trabajo, constituyéndose así en una medida para cuantificar el tamaño relativo de la fuerza laboral, de tal forma que si este indicador registra una tendencia creciente, significa que un mayor número de personas en edad de trabajar ${ }^{13}$ son activas, sea como ocupados o desempleados.

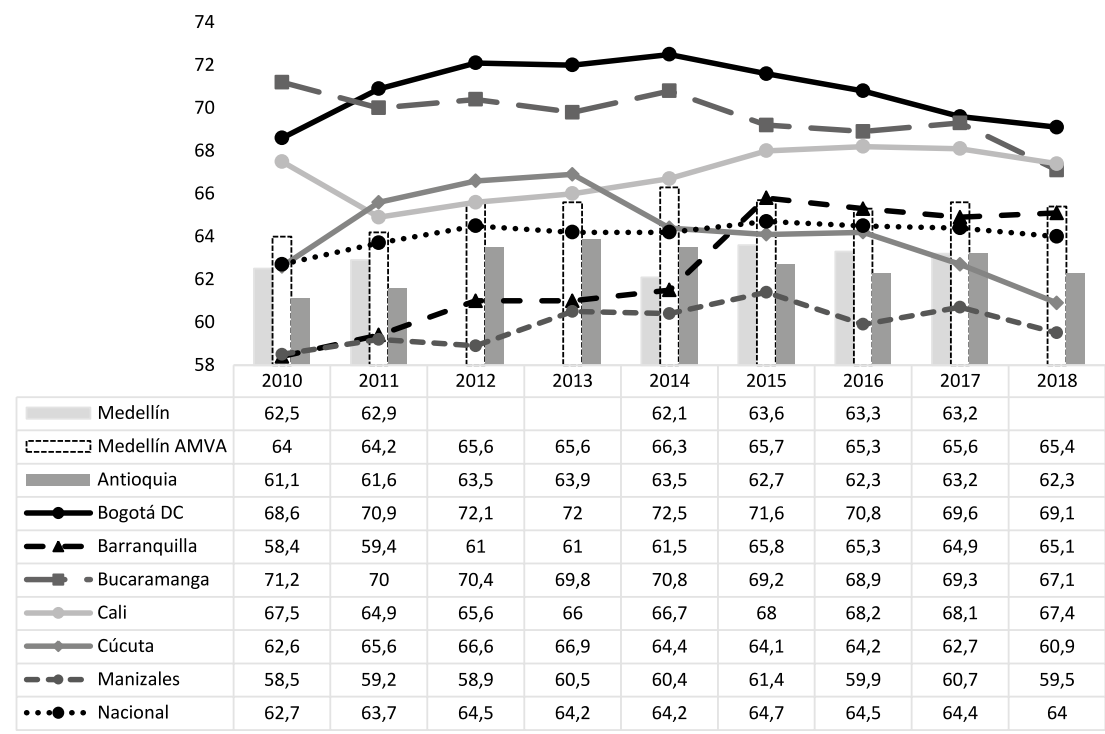

Figura 9. TGP para Medellín y otras ciudades: 2010-2018.

Fuente: el autor, con base en GEIH-DANE.

Desde 2011 es Bogotá la que registra la mayor TGP, siguiéndole Bucaramanga. En Medellín, por su parte, desde el 2015 esta viene cayendo y en 2017 se ubicó en el $63.2 \%$; mientras que al incluirle su área metropolitana sube al $65.6 \%$. La menor presión en el mercado de trabajo se presenta en Manizales, la cual en promedio se ubica en el $60 \%$. En todos los casos, aunque no se muestra, la mayor presión la ejercen los hombres, aunque la participación femenina viene creciendo en el tiempo. En este sentido, la problemática de pocas vacantes para un

13 En Colombia, la población en edad de trabajar (PET) es aquella que en zonas rurales tiene 10 años de edad o más, y en zonas urbanas, 12 o más. 
mercado en el que cada vez participan más las mujeres y los jóvenes renace de manera importante, por lo cual deben buscarse mecanismos que promuevan la creación de puestos formales. (Figura 9)

\section{Indicador 1.7 Tasa de desempleo juvenil}

Es importante identificar qué tan difícil es para los jóvenes (de 18 a 28 años) conseguir un trabajo en el país, y particularmente su primer empleo. Nuevamente Cúcuta se raja en materia laboral: desde el 2014 se ubica como la capital con mayor tasa promedio de desempleo en jóvenes, $(23.3 \%)$ y con tendencia alcista (al igual que Barranquilla, Bogotá, Bucaramanga y el agregado nacional). En Cali también preocupa el desempleo para este grupo etario. En el caso de Medellín, entre el 2010 y el 2014 se registró una tendencia a la baja (en 2014 se ubicó en el $15.2 \%$ ), pero a partir de este año viene en aumento continuo, fenómeno presente en casi todos los territorios analizados. En el país, en promedio, 17 de cada 100 jóvenes están desempleados. Este desempleo juvenil, aunque no se muestra, en términos generales viene afectando más a las mujeres que a los hombres. (Figura 10)

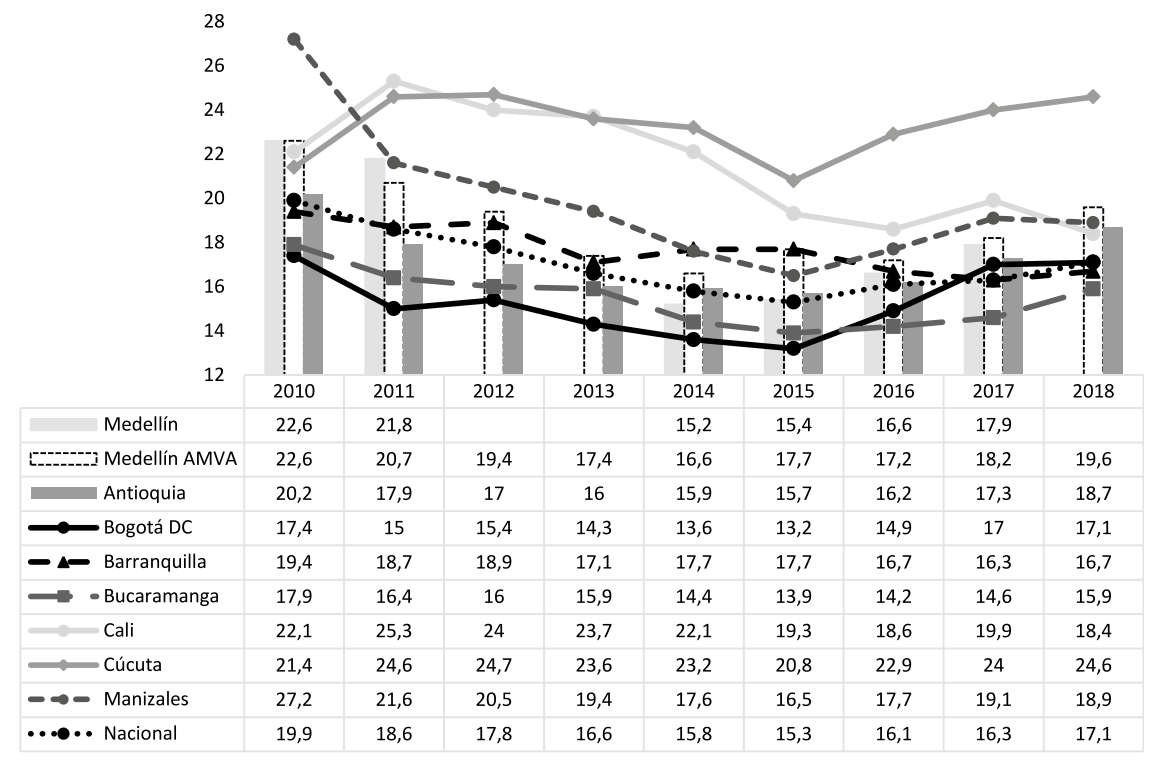

Figura 10. Tasa de desempleo juvenil para Medellín y otras ciudades: 2010-2018.

Fuente: el autor, con base en GEIH-DANE. 


\section{Indicador 1.8 Tasa de desempleo se- gún nivel educativo}

Según el nivel educativo y para 2017 exclusivamente, en Medellín AMVA, Antioquia y Bogotá, la población con educación media (como último nivel educativo) es la que registra un mayor desempleo (en promedio un $12.2 \%$ ); sin embargo, para el agregado nacional, esta problemática afecta más a los que tienen educación superior (en promedio el $11.3 \%$ en los últimos seis años), al igual que en Barranquilla, Bucaramanga y Manizales. Para el caso de Mede1lín, el $11.4 \%$ de los desempleados tiene hasta básica primaria y el $10.9 \%$ hasta media. Cúcuta es la que registra las mayores tasas de desempleo en todos los niveles educativos. La menor desocupación para los menos cualificados estaría relacionada con la alta informalidad del país y la mayor actividad de establecimientos comerciales (en comparación con la industria) (Figura 11). En síntesis, el país registra diferencias notables en su capacidad de absorber la necesidad de trabajo de los jóvenes, y en una proporción importante de los más cualificados. Y si los cualificados no están accediendo a empleos, no se puede hablar de una economía con puestos de trabajo decentes.

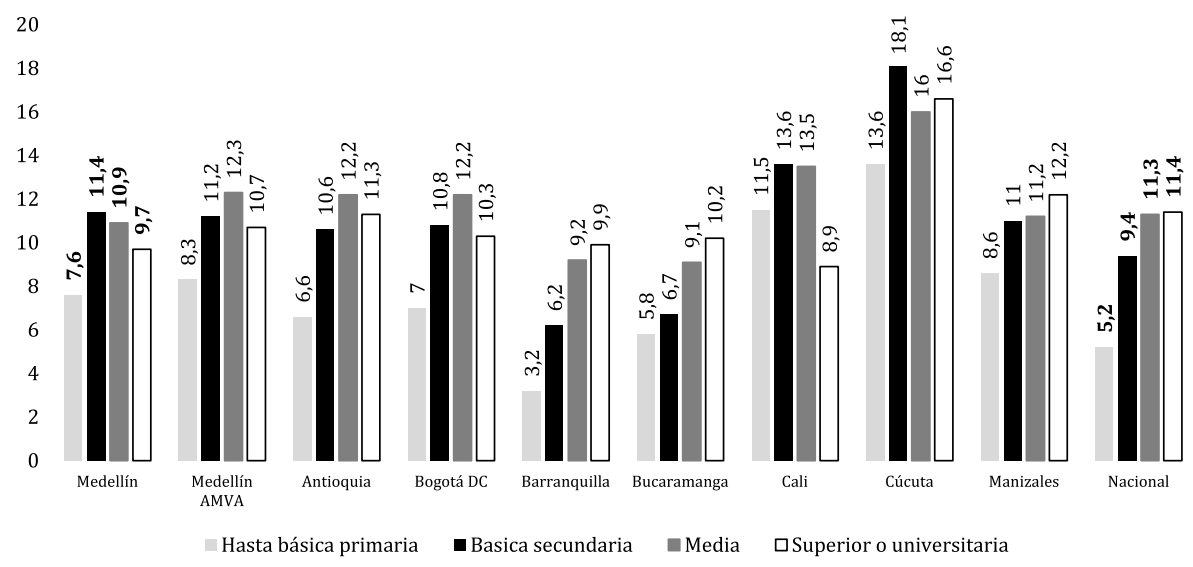

Figura 11. Tasa de desempleo según nivel educativo para Medellín y otras ciudades: 2017.

Fuente: el autor, con base en GEIH-DANE.

\section{Indicador 1.9 Perfil ocupacional}

Conviene identificar cuál es el perfil/ posición ocupacional característico en el país. Para la gran mayoría de las unidades geográficas analizadas, los trabajadores en su mayoría laboran en una empresa privada. Para Medellín esta participación ha estado por encima de la mitad (56.4\%), situación igual- mente presentada en Medellín AMVA, Antioquia, Bogotá y Manizales. En importancia le siguen los cuentapropistas, ratificando la relevancia de la informalidad en el país. Así que el hecho de que se registren alzas en la participación porcentual de trabajadores por cuenta propia o sin remuneración lleva a que el empleo sea menos decente. (Figura 12) 


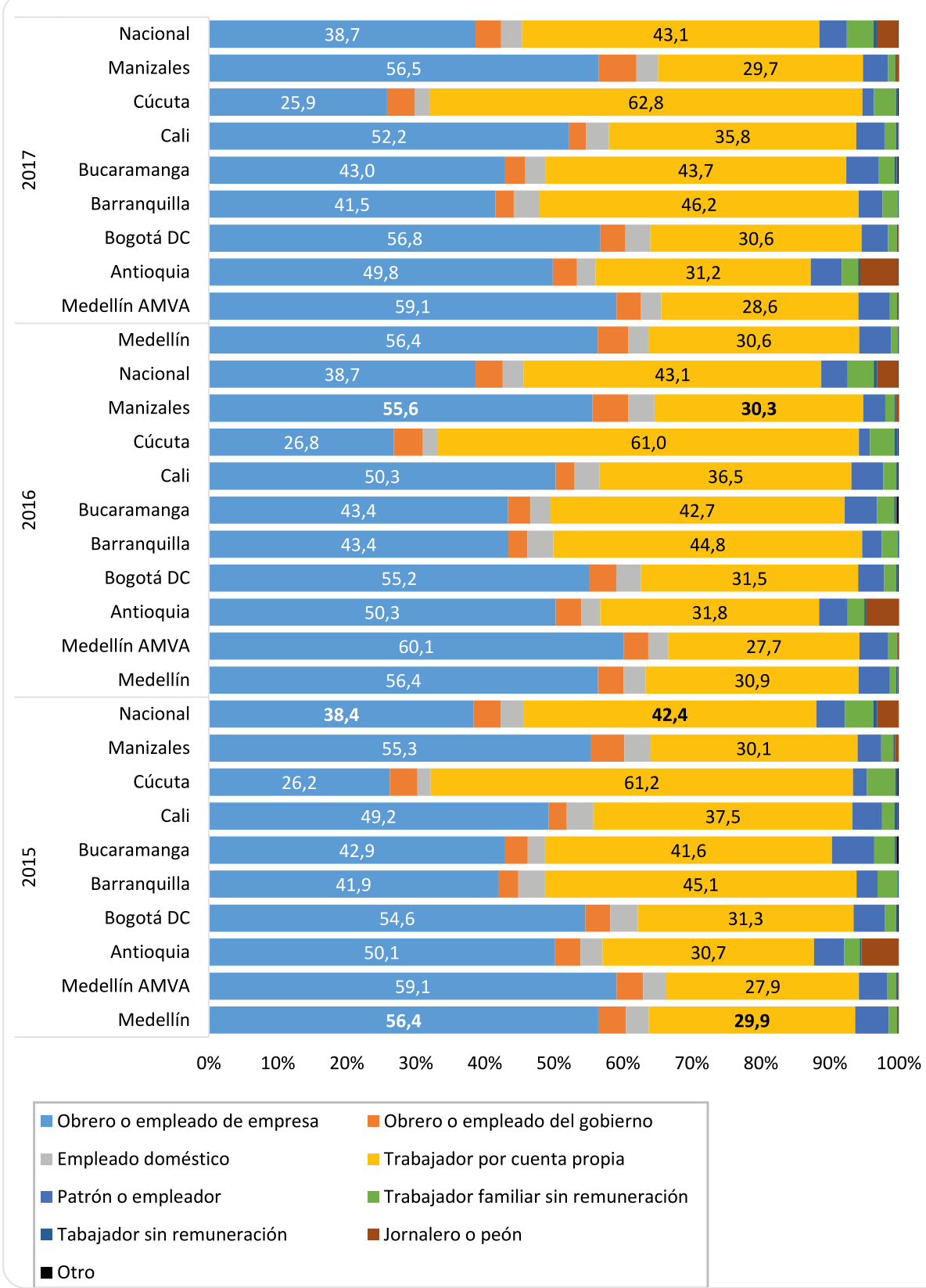

Figura 12. Perfil ocupacional para Medellín y otras ciudades: 2015-2017.

Fuente: el autor, con base en GEIH-DANE. 
Indicador 1.10 Ocupados cuenta propia y trabajadores familiares

La participación que tienen los trabajadores familiares y por cuenta propia, que por las particularidades de su contrato los hace más propensos a inestabilidad laboral y peores condiciones, genera alarma en las distintas ciudades, ya que estos tipos de contratos no caben en la concepción de trabajo decente. En Cúcuta, por ejemplo, el 66\% de los ocupados cumplían las anteriores características en el 2017, situación que ha venido en aumento desde el 2010. Medellín por su parte, cerró el 2017 con una participación del $31.7 \%$; mientras que Medellín AMVA fue ligeramente inferior ubicándose en el $29.6 \%$, aumentando para 2018 al $30.4 \%$. Desde el 2013, esta última viene registrando la menor tasa de todas las capitales consideradas. En el agregado nacional, en promedio 4 de cada 10 ocupados son cuentapropistas o trabajadores familiares, lo cual indica una condición que atenta contra el trabajo decente. (Figura 13)

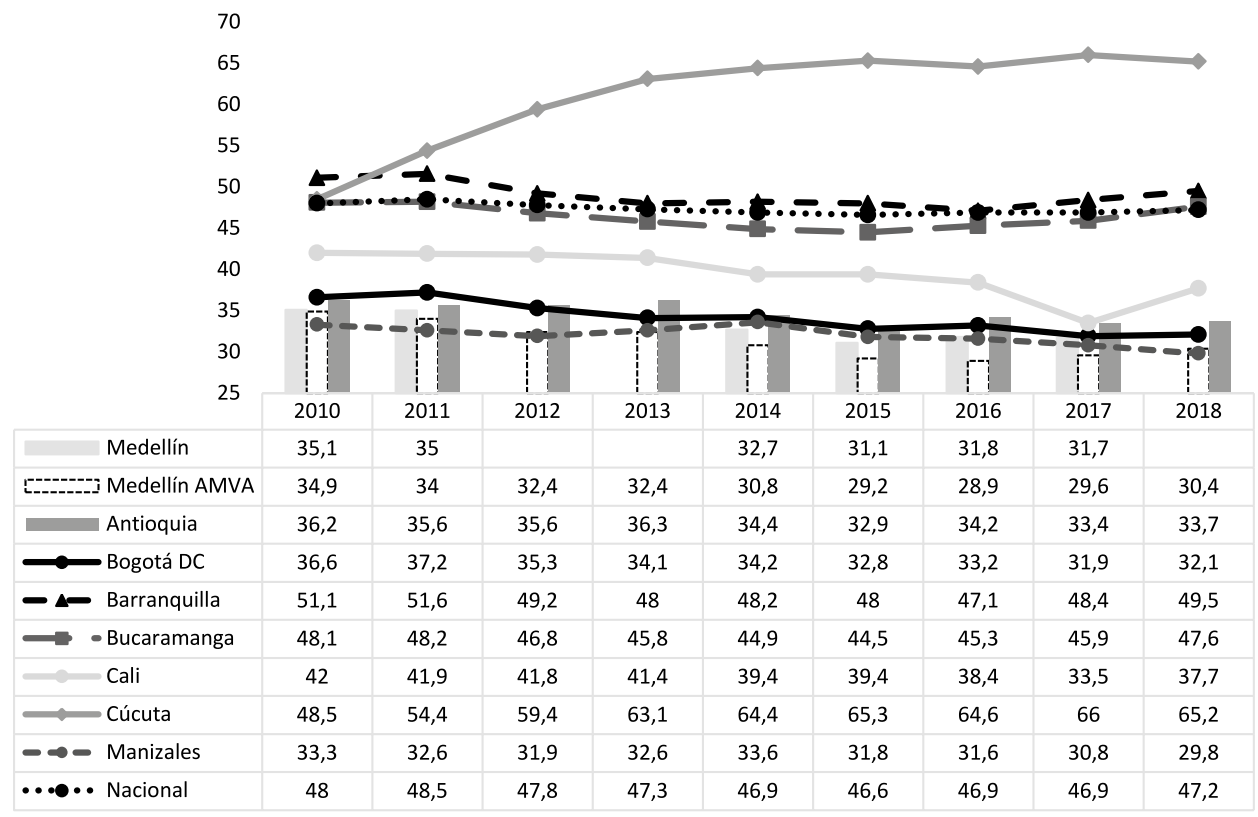

Figura 13. Porcentaje de ocupados cuenta propia y trabajadores familiares para Medellín y otras ciudades: 2010-2018.

Fuente: el autor, con base en GEIH-DANE. 
Indicador 1.11 Porcentaje de asalariados no agrícolas

En promedio, en el ámbito nacional el $41.2 \%$ de los ocupados son asalariados no agrícolas. Medellín AMVA, Manizales y Bogotá son las capitales con mayor porcentaje, lo cual evidencia mejores condiciones para sus trabajadores $\mathrm{y}$, por tanto, mayor cercanía a lo que se concibe como trabajo decente. Caso opuesto es el de Cúcuta (en promedio $30.6 \%$ ) y el agregado nacional. (Figura 14)

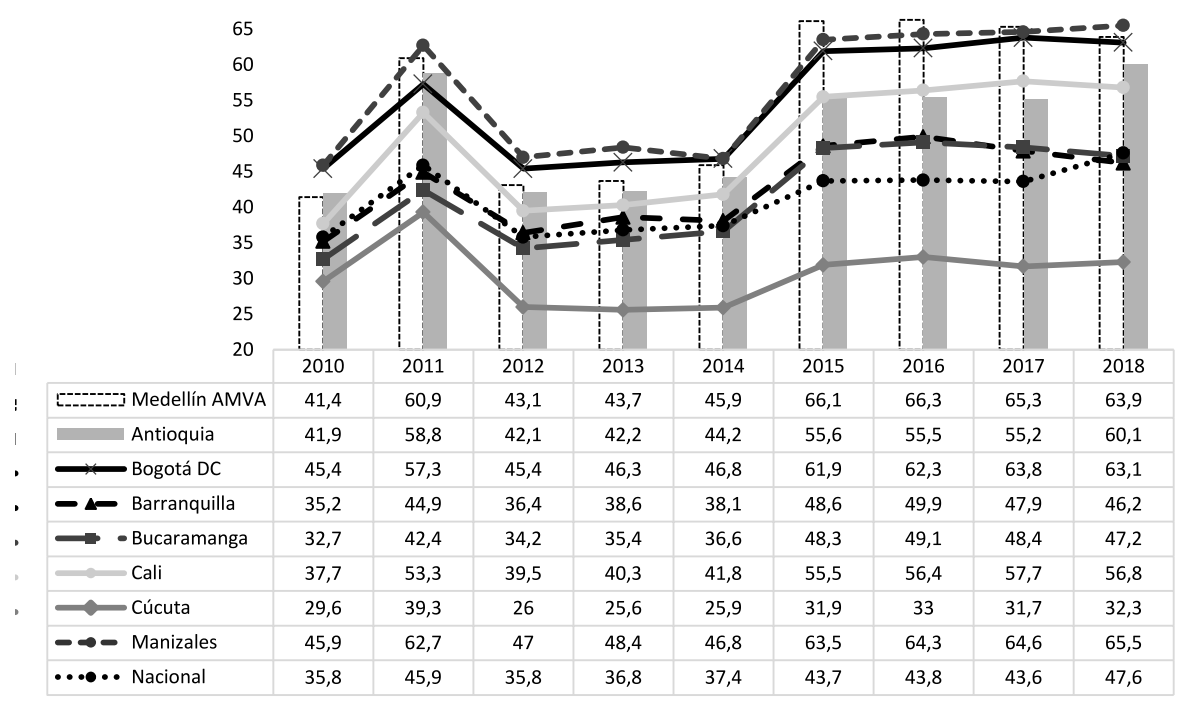

Figura 14. Porcentaje de asalariados no-agrícolas del total de ocupados: 2010-2018.

Fuente: el autor, con base en GEIH-DANE.

Dimensión 2: ingresos suficientes y productividad

Bajo la concepción del trabajo decente, no solo es importante que las personas que estén buscando empleo lo encuentren, sino que cuenten con las condiciones suficientes para el desarrollo pleno del ser humano y también que la remuneración en el trabajo les permita suplir todas sus necesidades, al menos las básicas ${ }^{14}$.

\section{Indicador 2.1 Tasa de ocupados pobres}

Representa el porcentaje de la población que, si bien se encuentra ocupada, vive en la pobreza. Esto es, el ingreso

14 Es importante mencionar que el valor a 2018 de los indicadores que emplean para su cálculo la variable total de ingresos laborales, puede registrar diferencias importantes con respecto a los otros años, ya que en este último año no se tuvo acceso a la variable ajustada por imputación y subdeclaración de ingresos, que era suministrada en años previos directamente por Mintrabajo. 
familiar per cápita es inferior a la línea de pobreza según año y territorio. En el ámbito nacional, en promedio el $33.5 \%$ son ocupados pobres, mientras que en Medellín son el $20 \%$. Esta tasa es menor para Bucaramanga (11.6\%), Bogotá (11.9\%) y Manizales (18.9\%). Mientras que, en Cúcuta, Barranquilla, Antioquia y el agregado nacional en toda la serie han sido superiores (Figura 15). Hay una diferencia importante, especialmente desde el 2014, entre Medellín y Medellín AMVA (alrededor de 6 puntos porcentuales), que indica que la inclusión de otros municipios en el cálculo del indicador afecta el resultado de la capital antioqueña. En síntesis y en promedio, en el país 3 de cada 10 ocupados viven en hogares cuyos ingresos no superan la línea de pobreza, situación que no la concibe el trabajo decente.

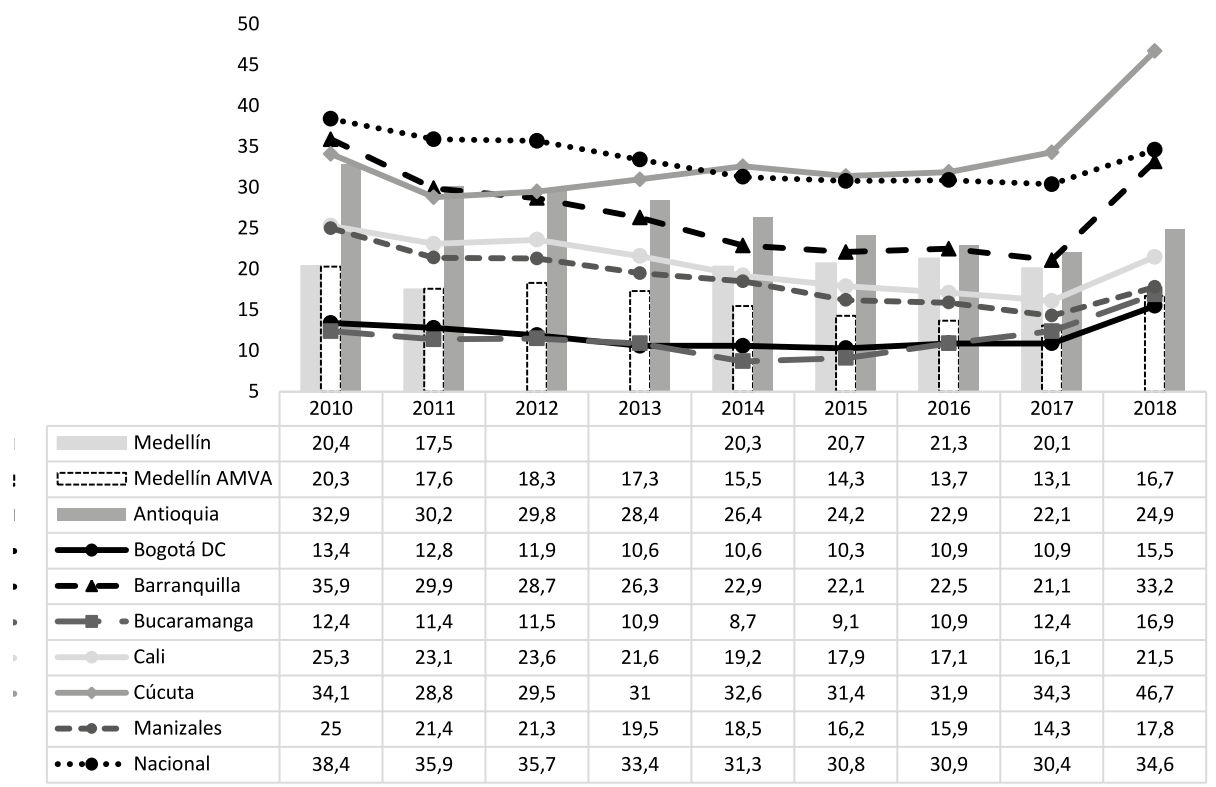

Figura 15. Tasa de ocupados pobres para Medellín y otras ciudades: 2010-2018.

Fuente: el autor, con base en GEIH-DANE.

Luego, que 3 de cada 10 ocupados sean empleados pobres genera una alarma, porque representan los hogares cuyos ingresos totales no superan la línea de pobreza, que por cierto es inferior al costo de la canasta básica. También hay que tener en cuenta, que en el país para el 2018 alrededor del $45 \%$ de los ocupados devengan hasta un smmlv, un $38 \%$ hasta dos smmlv y solo el $17 \%$ más de dos. Aquí las mujeres presentan una desventaja (sus porcentajes son respectivamente $52 \%, 33 \%$ y $15 \%$ vs. el $40 \%$, $42 \%$ y $19 \%$ para los hombres). 
La política pública debe focalizarse, entonces, en la promoción de empleos suficientes y productivos, acompañada de una política de redistribución del ingreso que permita que las rentas familiares logren estar por encima del costo de la canasta básica y que se pueda de alguna forma blindar a los trabajadores de salarios excesivamente bajos o, en otros términos, de empleos no decentes.

\section{Indicador 2.2 Tasa de asalariados con bajos ingresos}

Este indicador reporta el número de asalariados remunerados con menos de dos tercios de la mediana del salario, por hora según territorio y año, respecto del total de asalariados. En 2017 y para Colombia, el $14.9 \%$ de los asalariados obtuvieron bajos ingresos, mientras que en Medellín fue el 15.2\% muy superior al de Medellín AMVA (8.4 \%) (Figura 16). Lo positivo es que, en general, para todas las unidades geográficas de interés, este indicador viene con tendencia bajista desde el 2010. Aunque no se muestra, al analizar este indicador por nivel educativo, se evidencia que los asalariados que obtienen bajos ingresos corresponden a aquellos que cuentan con educación incompleta, ya sea porque no tienen estudios o porque solo terminaron primaria o secundaria.

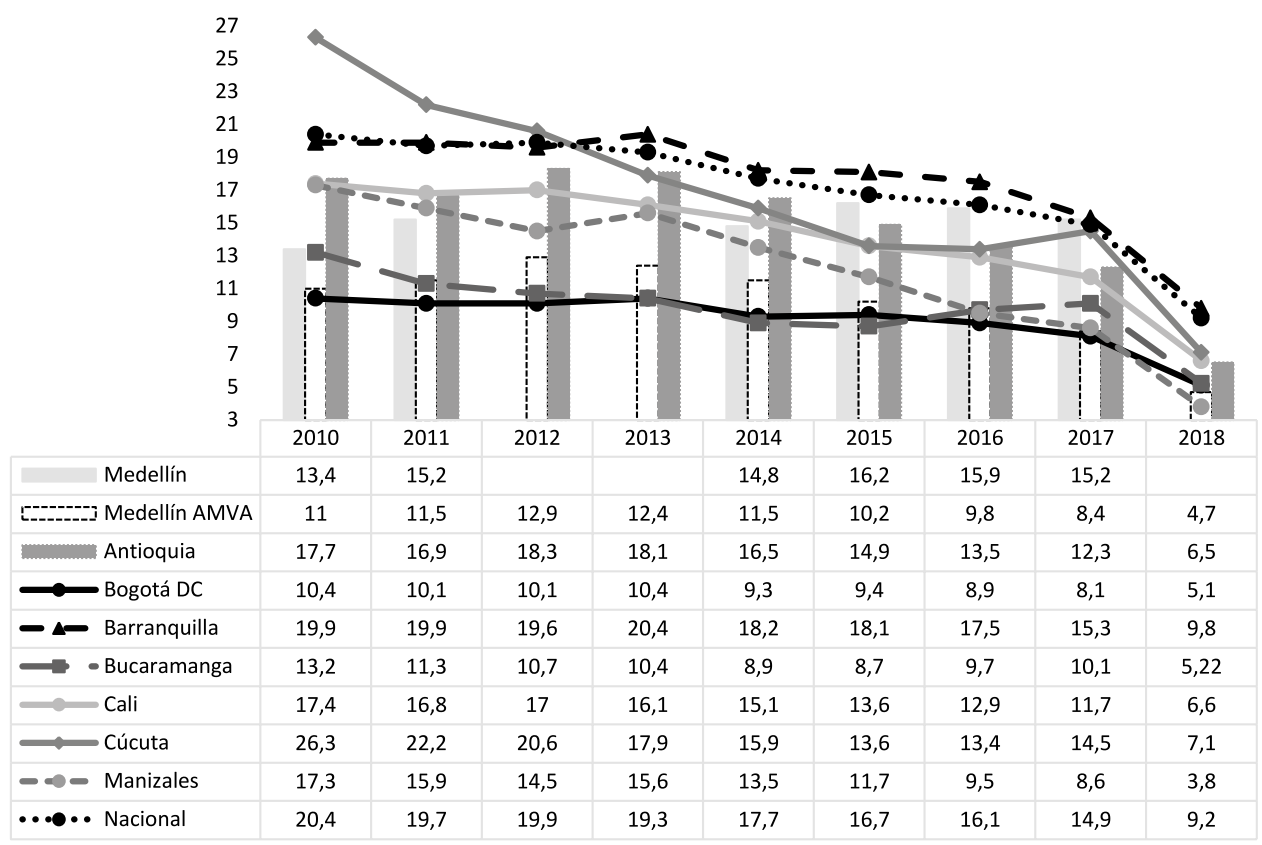

Figura 16. Tasa de asalariados con bajos ingresos para Medellín y otras ciudades: 2010-2018.

Fuente: el autor, con base en GEIH-DANE. 
Indicador 2.3 Ingresos laborales medios por hora

Este indicador se construye con el número de horas trabajadas al mes y la remuneración mensual. La capital del país, como es de esperarse por el mayor costo de vida, es la que mejor remunera a sus empleados, le sigue Medellín con y sin su área metropolitana. Si bien los ingresos medios en todas las unidades registran una tendencia al alza justificada en parte por el aumento en el costo de vida (inflación), la mayor tasa media de variación la registra Cúcuta (6.9\%), seguida de Medellín (5.7 \%) (Figura 17).

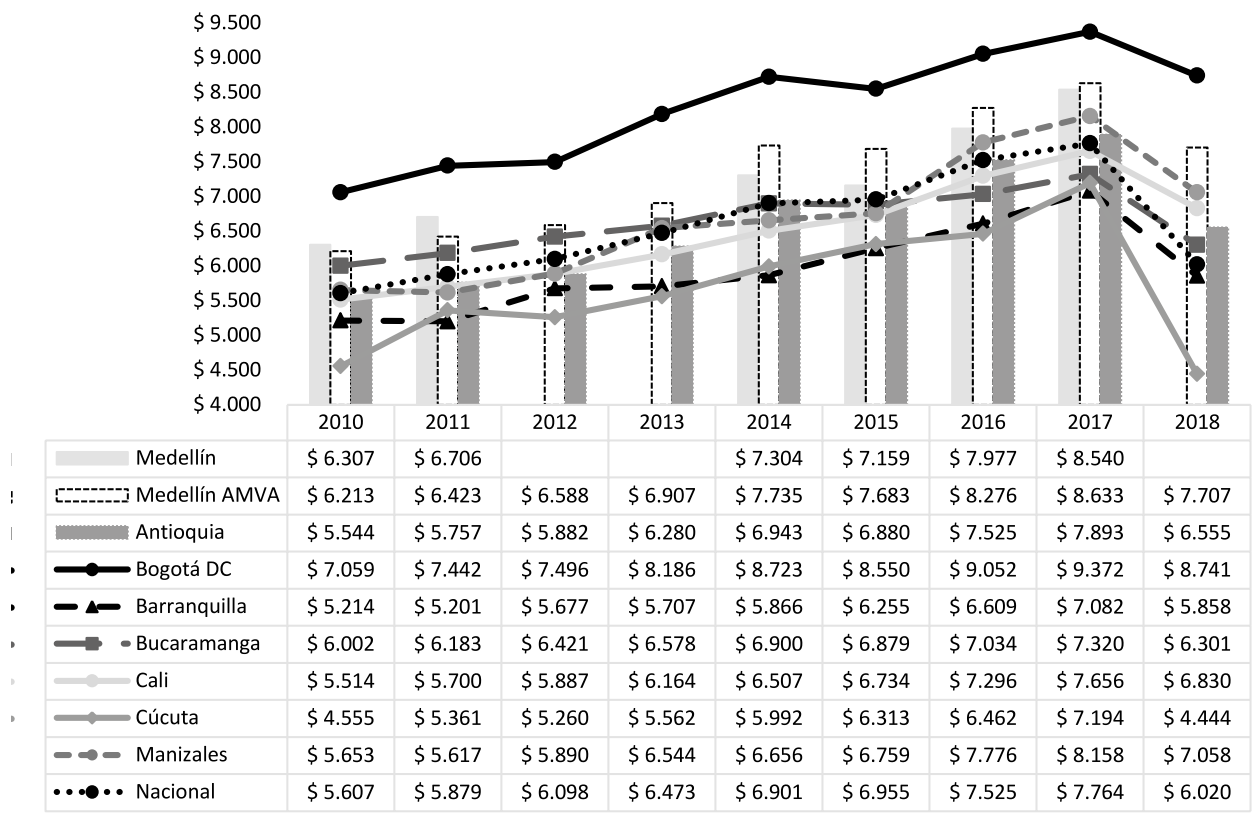

Figura 17. Ingresos laborales medios por hora para Medellín y otras ciudades: 2010-2018.

Fuente: el autor, con base en GEIH-DANE.

\section{Indicador 2.4 Salario promedio real}

Para eliminar el efecto inflacionario presentado en el anterior indicador, se calcula el salario real deflactando la remuneración mensual con el IPC. Bogotá nuevamente registra el mayor salario medio real a lo largo de la serie, siguiéndole Medellín y Medellín
AMVA. Cúcuta, por el contrario, es la capital con menores ingresos reales desde el 2012 (Figura 18). Aquí se confirman las disparidades importantes en términos de remuneración, lo que motiva entre otros fenómenos, la conmutación laboral. Y aquí, aunque en el marco del trabajo decente no se menciona específicamente la importancia que 
la distancia existente entre el lugar de residente y el de trabajo sea la mínima posible, cuando se consideran los tiempos de desplazamientos que aumentan por el mayor tráfico y que se agravan con las manifestaciones sociales, un trabajo decente implica necesariamente la disponibilidad de más tiempo para la familia y otras actividades.

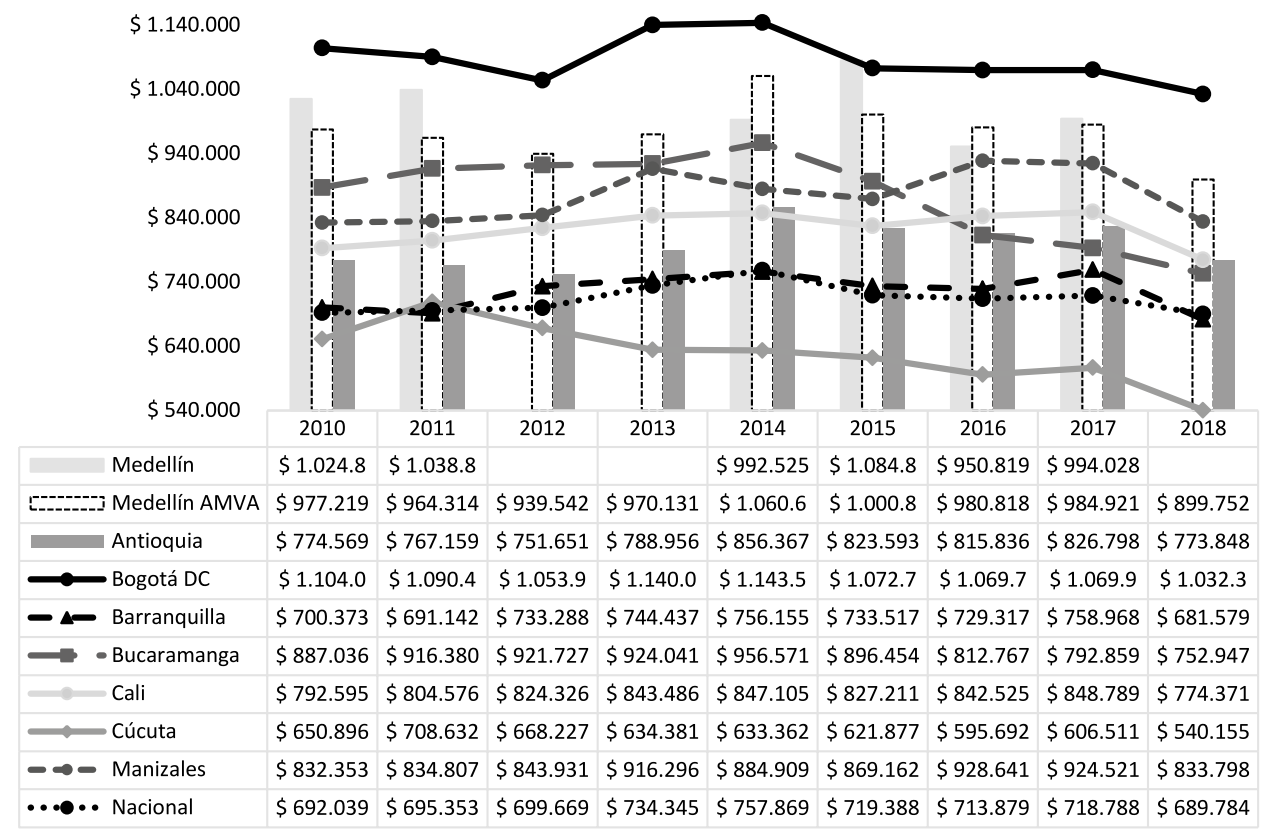

Figura 18. Salario promedio real para Medellín y otras ciudades: 2010-2018.

Fuente: el autor, con base en GEIH-DANE.

Indicador 2.5 Salario mínimo como porcentaje del salario mediano

La proporción del salario mínimo mensual legal vigente (smmlv) respecto del salario mediano mensual de cada unidad geográfica indica que es Cúcuta la ciudad que, desde el 2013, registra la mayor participación (en 2018 cerró con el $111 \%$ y en promedio es del $100 \%$ ), mientras que Medellín registra una diferencia importante a favor (de al menos 5 puntos porcentuales (pp)) respecto de Medellín AMVA, aunque en mejor posición están Bogotá y Bucaramanga ${ }^{15}$. En particular, para el 2017 Medellín registró una participación de $81.9 \%$, lo que significa que la mediana del salario mensual en la capital de Antioquia fue superior al smmlv (Figura 19).

15 Bajo la lógica del trabajo decente, el comportamiento deseable de este indicador es disminuir. Valores por debajo de cien en este indicador evidencian una tendencia a remunerar los empleos con un pago superior al smmlv. 
Los hallazgos en esta dimensión evidencian, por un lado, importantes diferencias espaciales en las remuneraciones de los trabajadores y por otro, que si bien los salarios en el país pueden aproximarse desde abajo al salario mínimo y mediano, hay un porcentaje considerable (en el 2018 de $34.6 \%$ ) de ocupados en condiciones de pobreza. En este sentido, los planes locales de empleo deben promover la creación de vacantes con remuneraciones suficientes.

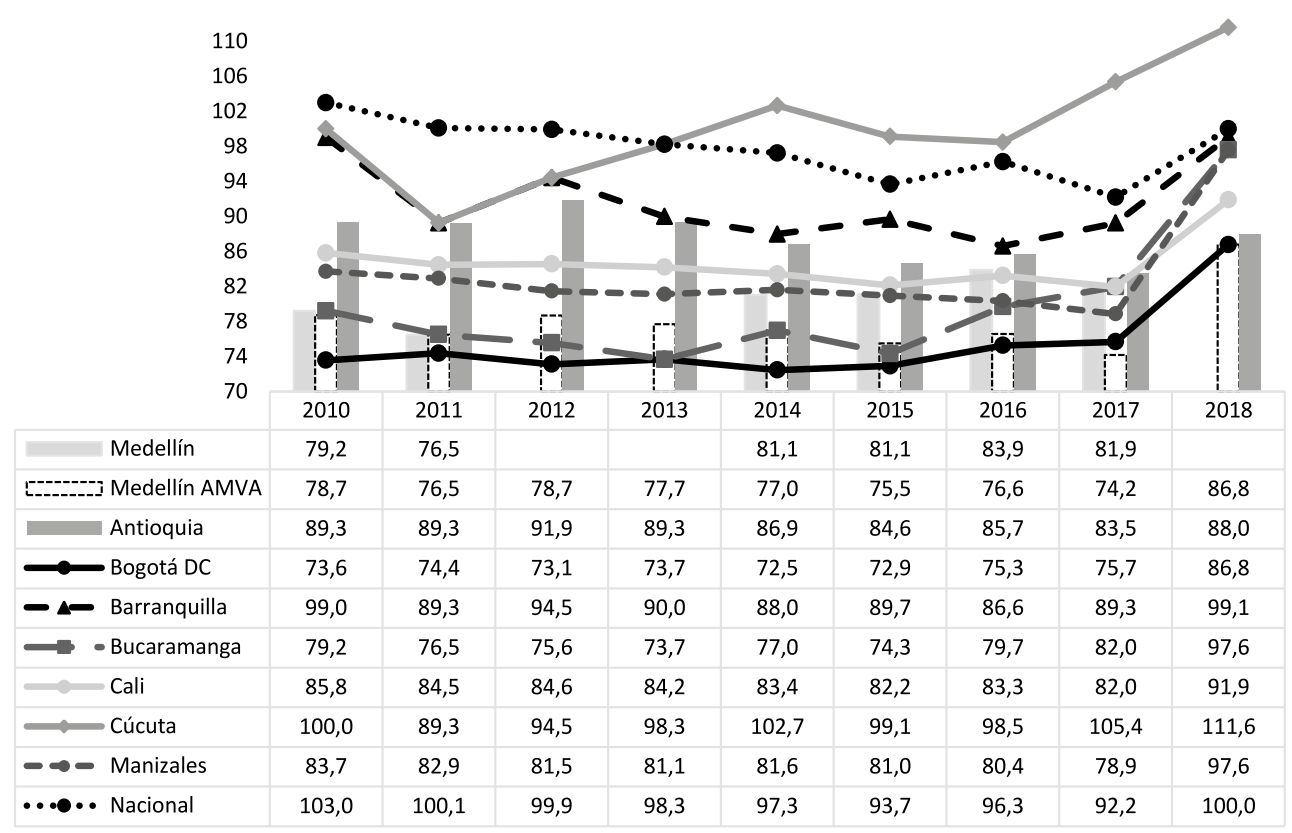

Figura 19. Salario mínimo como porcentaje del salario mediano para Medellín y otras ciudades: 2010-2018.

Fuente: el autor, con base en GEIH-DANE.

Dimensión 3: tiempo de trabajo decente

Los indicadores aquí tienen que ver con la jornada laboral y la situación de subempleo, este último característico de mercados laborales informales. La intención es examinar si a los trabajadores, en el marco de su desarrollo humano, les queda tiempo para su vida personal y familiar.

\section{Indicador 3.1 Trabajo excesivo}

Este indicador reporta el porcentaje de los ocupados que laboran en la semana más de las 48 horas legales. La evidencia indica que en Cúcuta el empleo es absorbente, puesto que en toda la 
serie disponible, esta capital registra el mayor porcentaje (en promedio el $45.5 \%$ ) -siguiéndole Bucaramanga con el $38.5 \%$ - quizá motivado por el mayor desempleo y menores ingresos que obliga a las personas a aceptar cualquier tipo de empleo.

En el ámbito nacional, en el 2017 el $28.4 \%$ de los ocupados trabajaron más de las 48 horas, mientras que en Medellín fue del 29\% (superior a Medellín AMVA, que registró el $26.9 \%$ ). Barran- quilla fue la ciudad que reportó la jornada laboral más corta en casi toda la serie (en promedio un $26.5 \%$ ). En términos agregados, entre el $28 \%$ y el $30 \%$ de los ocupados del país laboraron más de las 48 horas a la semana. Es de destacar la tendencia a la baja que se registró en casi todos los territorios (en el país pasó del $34.4 \%$ en 2010 al $27.7 \%$ en el 2018 ), fenómeno deseable en la concepción del trabajo decente, siempre y cuando no se traduzca en disminución de salarios. (Figura 20)

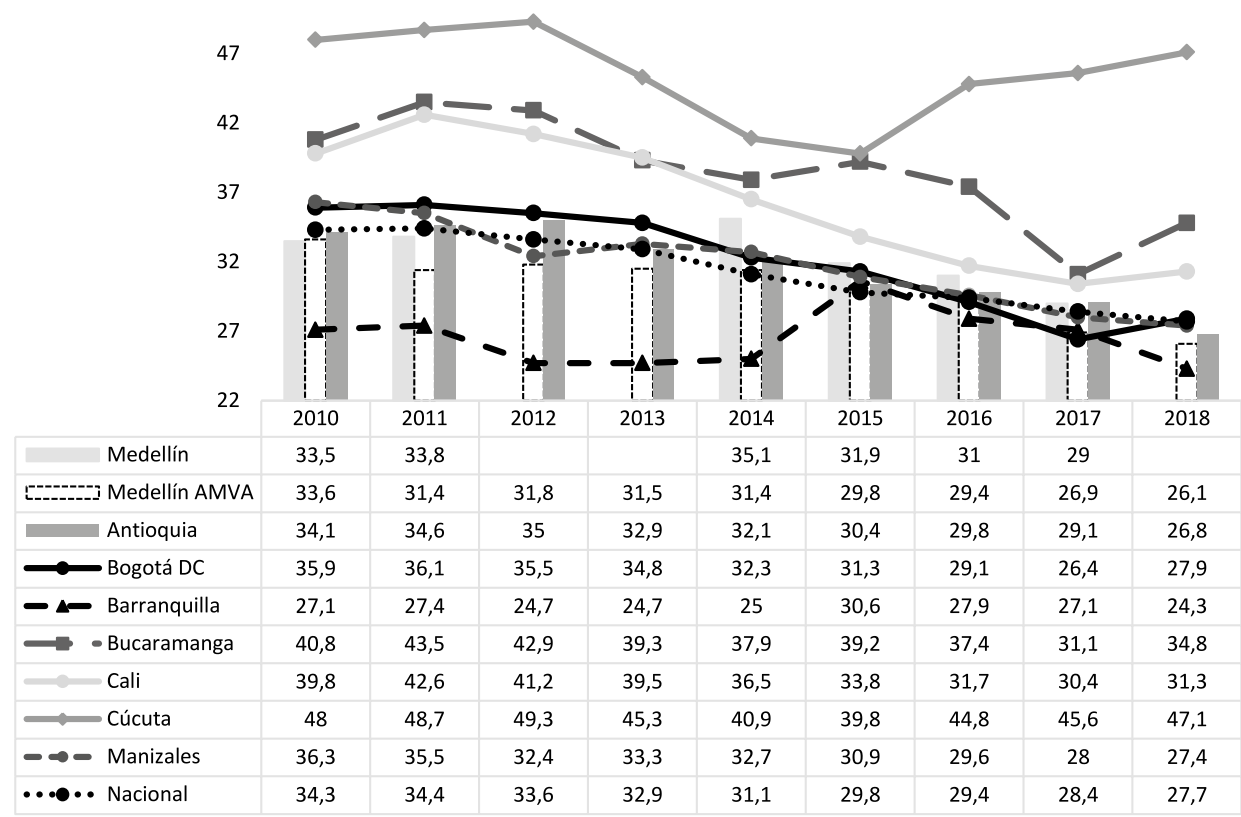

Figura 20. Tasa de trabajo excesivo para Medellín y otras ciudades: 2010-2018.

Fuente: el autor, con base en GEIH-DANE. 


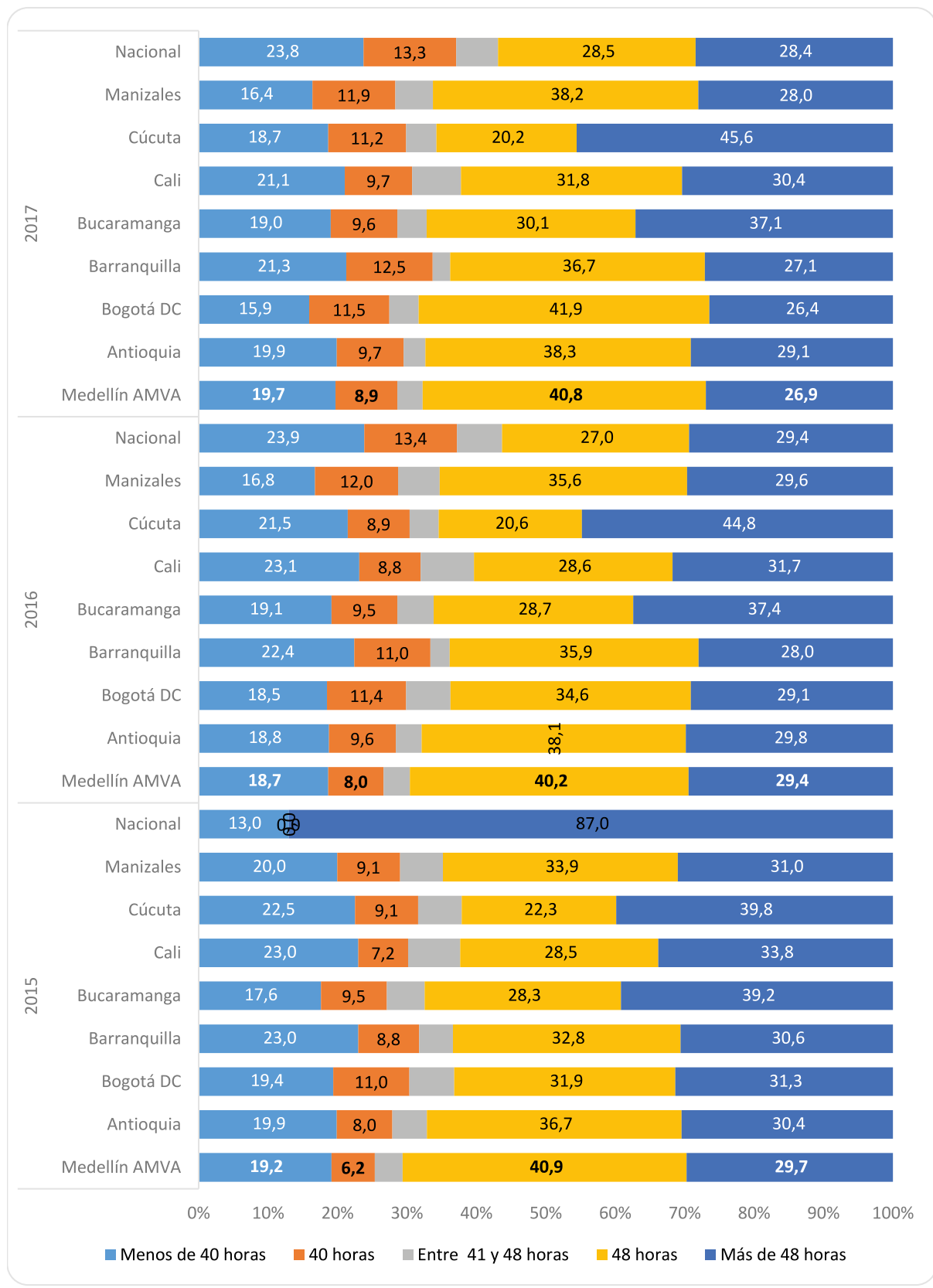

Figura 21. Porcentaje de ocupados según rango de horas laboradas en la semana para Medellín y otras ciudades: 2015-2017.

Fuente: el autor, con base en GEIH-DANE. 
Indicador 3.2 Porcentaje de ocupados según rango de horas de labor

Como complemento al indicador anterior, se reporta uno que mida la distribución de la población ocupada por rangos de hora trabajada a la semana. Como es de esperar, en la mayoría de las ciudades los ocupados laboran la jornada legal, exceptuando el caso de Cúcuta. Y de acuerdo con la normatividad vigente, se considerarían no decentes los empleos donde se les exige a sus trabajadores laborar más de las 48 horas, o en los cuales se laboran horas extras sin pago.

Que, en términos generales, en el país 3 de cada 10 ocupados laboren más de las 48 horas semanales, especialmente los hombres (3.8\% vs. $19.6 \%$ de las mujeres), sugiere revisar si los empleadores están respetando los contratos de trabajo con respecto al tiempo laboral, si se les están reconociendo de hecho horas extras o si, por el contrario, hay evidencia de explotación laboral, cosa que atenta contra el trabajo decente. (Figura 21)

\section{Indicador 3.3 Tasa de subempleo obje- tivo (TSO)}

Son ocupados en situación de subempleo aquellos que tienen el deseo de me- jorar sus condiciones laborales (ya sea por ingresos, competencias o jornada de trabajo), y han realizado alguna gestión para materializar su aspiración y están en disposición de efectuar el cambio (DANE, 2016). En los dos últimos años, quienes más presentan esta situación son los ocupados de Cúcuta, seguidos por los de Cali y Barranquilla.

Cúcuta presentó en el 2016 una TSO de $15.4 \%$; un año después aumentó $1 \mathrm{pp}$. En Medellín, en el 2017 no se presentó ningún cambio frente al año anterior $(7.6 \%)$ y fue inferior a la registrada por Medellín AMVA (que en el 2016 registró una TSO de $11 \%$ y en 2017 de $10.5 \%$ y también del agregado nacional (Figura 22). En general, se podría decir que en el país en promedio 11 de cada 100 ocupados están en situación de subempleo objetivo. Cabe destacar que desde el 2010 esta situación viene con tendencia a la baja para el agregado nacional y en varios territorios del país, lo cual es una buena señal para el trabajo decente, porque una economía con empleos decentes debe registrar mínimas ocurrencias de subempleo por la mayor satisfacción que tendrían los trabajadores de su actividad. 


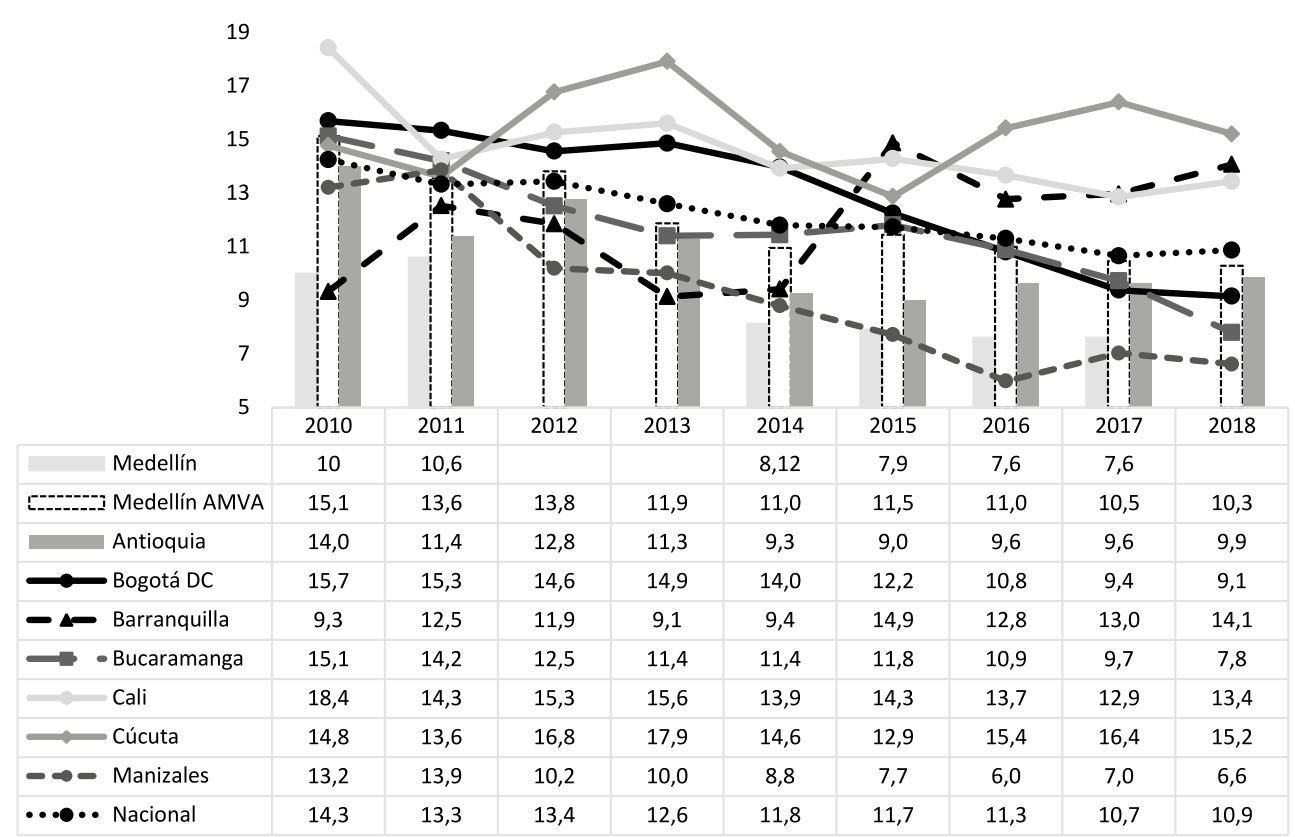

Figura 22. Tasa de subempleo objetivo para Medellín y otras ciudades: 2010-2018.

Fuente: elaborador del autor, GEIH-DANE.

Dimensión 4: conciliación del trabajo, la vida familiar y la vida personal

Es característico de mercados de trabajo altamente informales como el colombiano que existan empleos sin remuneración. En esta dimensión se presenta un indicador relacionado.

\section{Indicador 4.1 Tasa de tiempo de trabajo no remunerado frente al remunerado}

Este indicador corresponde a la razón del número de horas semanales destinadas a actividades no remuneradas frente al número de horas semanales destinadas a trabajo remunerado. En este orden de ideas, el valor ideal de esta razón es que sea cercano a 0 , porque ello indicaría que el trabajo no remunerado sería nulo, lo que implicaría que el empleo en la economía se acercaría a la concepción de trabajo decente. En 2018 Barranquilla y Cúcuta presentan la mayor proporción de empleos no remunerados (31.9 y 28.4 respectivamente), aunque con el promedio, son Bucaramanga y Cali las de mayor tasa (27.2 y 27.1 respectivamente). En el ámbito nacional, el promedio es de 29 y estuvo constante entre el 2017 y 2018 (Figura 23).

En el país, las ocupaciones no remuneradas son en su mayoría las relacionadas 
con el hogar y el cuidado de propiedades, ancianos y niños. Situación que nos lleva a pensar que toda actividad que involucre un costo de oportunidad para la persona debería ser de algún modo remunerada. Estos son precisamente los trabajos decentes.

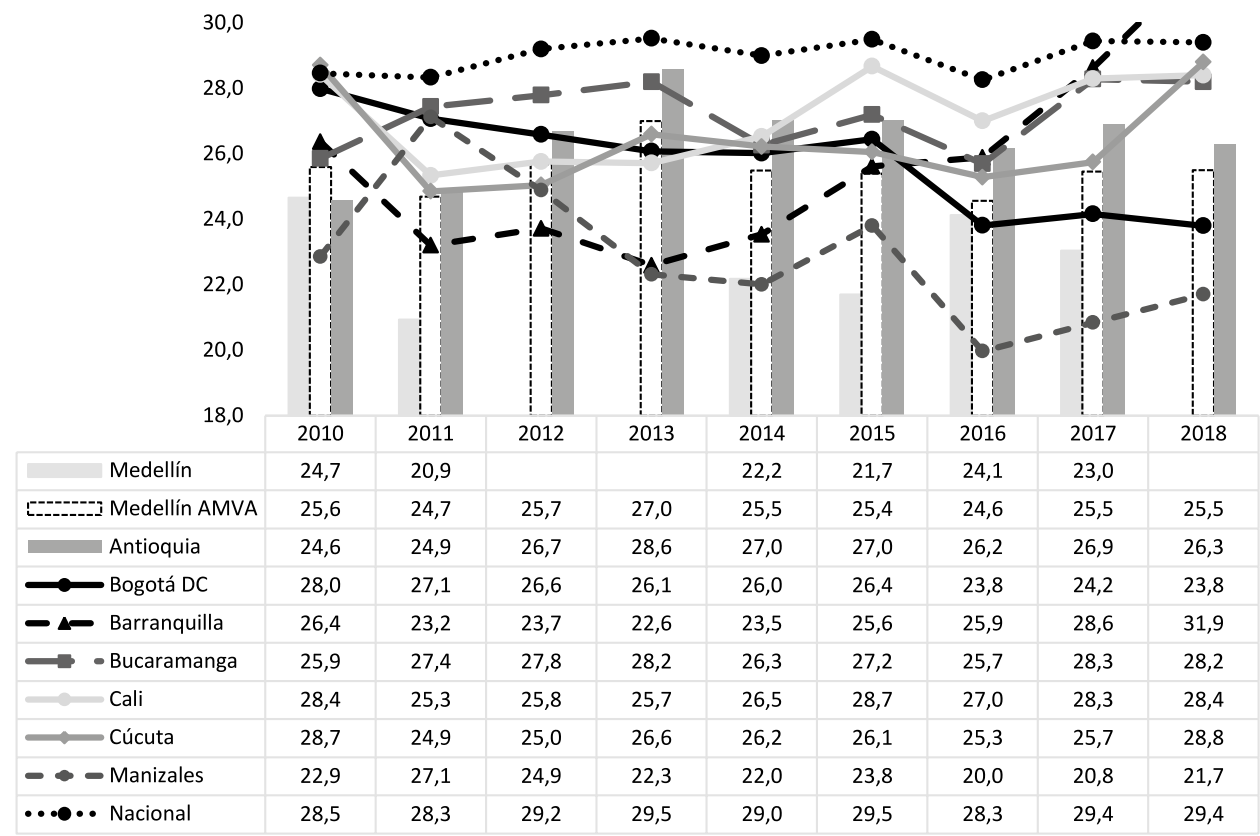

Figura 23. Tasa de tiempo de trabajo no remunerado frente al remunerado para Medellín y otras ciudades: 2010-2018.

Fuente: el autor, con base en GEIH-DANE.

Dimensión 5: trabajo que debería abolirse

Dentro de los trabajos que deberían abolirse están el infantil y el forzoso. Usualmente en la literatura se encuentra la tasa de trabajo infantil calculada para niños entre los 10 y 17 años (como generalmente se toma en el país). Pero dadas las condiciones de pobreza que empujan a los niños a trabajar, suele condicionarse trabajo infantil si el niño trabaja más de 15 horas. En este estudio se opta por reportar el primero, para reflejar mejor la realidad.

\section{Indicador 5.1 Tasa de trabajo infantil}

En los últimos siete años, entre 7 y 10 de cada 100 niños trabajan en el país ${ }^{16}$. 
La situación es menos preocupante en Manizales, en la que la tasa se ubicó desde el 2016 en el $1 \%$, siendo más baja que la reportada por Medellín (que en 2017 fue del $3.6 \%$ ) (Figura 24). Es de destacar la disminución continua de este fenómeno para el agregado nacional y Bucaramanga. Sin duda, en una economía donde los niños trabajan, no hay trabajo decente. Para ello, los hacedores de política deben facilitar el acceso y la permanencia de los menores en el sistema educativo e implementar fórmulas para combatir aquellas mafias que suelen estar detrás del trabajo infantil. Aquí hay que destacar el esfuerzo del Gobierno en crear por primera vez la línea de política pública para la prevención y erradicación del trabajo infantil y la protección integral al adolescente trabajador (Mintrabajo, 2017).

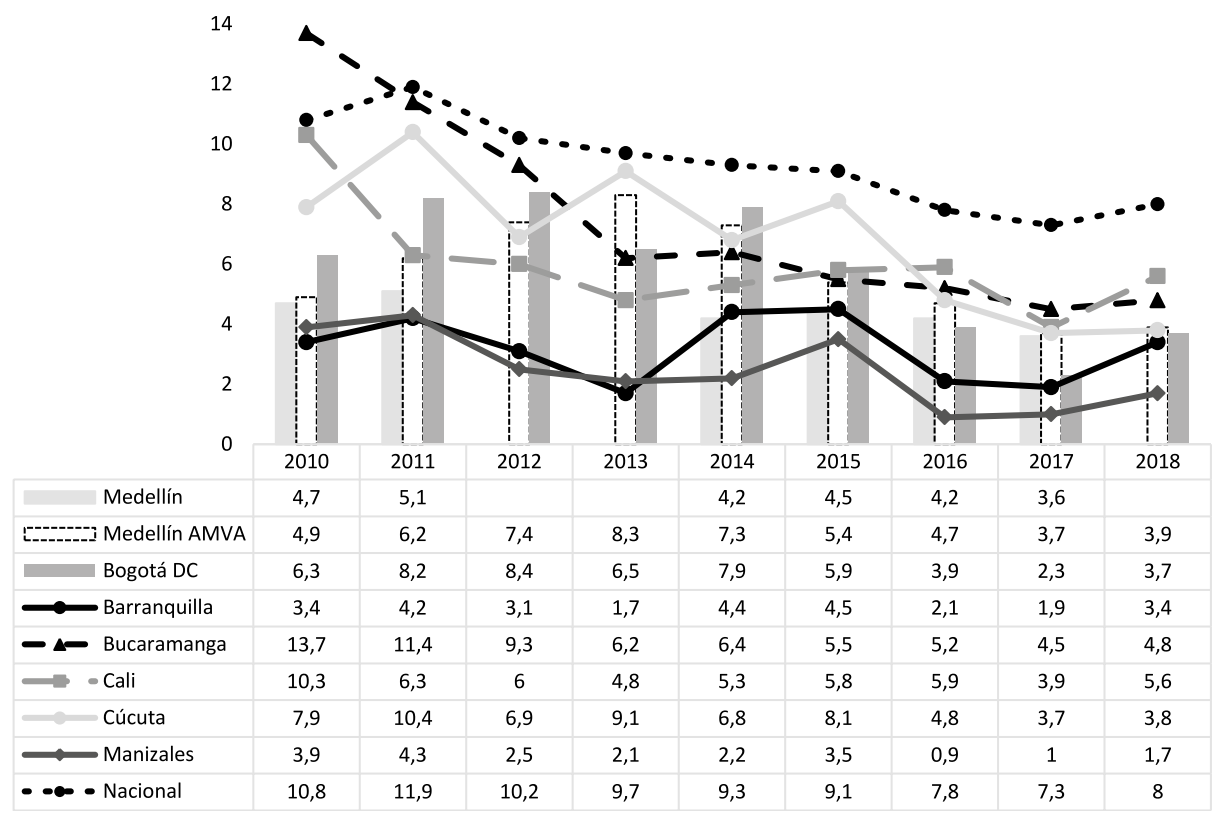

Figura 24. Tasa de trabajo infantil para Medellín y otras ciudades: 2010-2018.

Fuente: el autor, con base en GEIH-DANE.

Dimensión 6: estabilidad y seguridad del trabajo

Aquí se reportan dos indicadores sobre la estabilidad y seguridad en el trabajo. El primero sirve para identificar el grado de precariedad del empleo, el segundo permite determinar la antigüedad. Esta dimensión posibilita diferenciar a los trabajadores cuyos empleos se caracterizan por alguna permanencia relativa, de aquellos cuyos trabajos no ofrecen una relación de larga duración. Los 
indicadores se dan en términos de la participación del empleo en categorías de trabajo inestable.

\section{Indicador 6.1 Tasa de trabajo precario}

Cuando el trabajador sufre inseguridad, incertidumbre, posibilidad de despido rápido y falta de garantías en las condiciones de su empleo, se habla de trabajo precario. Aquí el factor tiempo (si es fijo o hay intermediario en la contratación) y el tipo de contrato (si es verbal) es fundamental para considerar el empleo como precario.

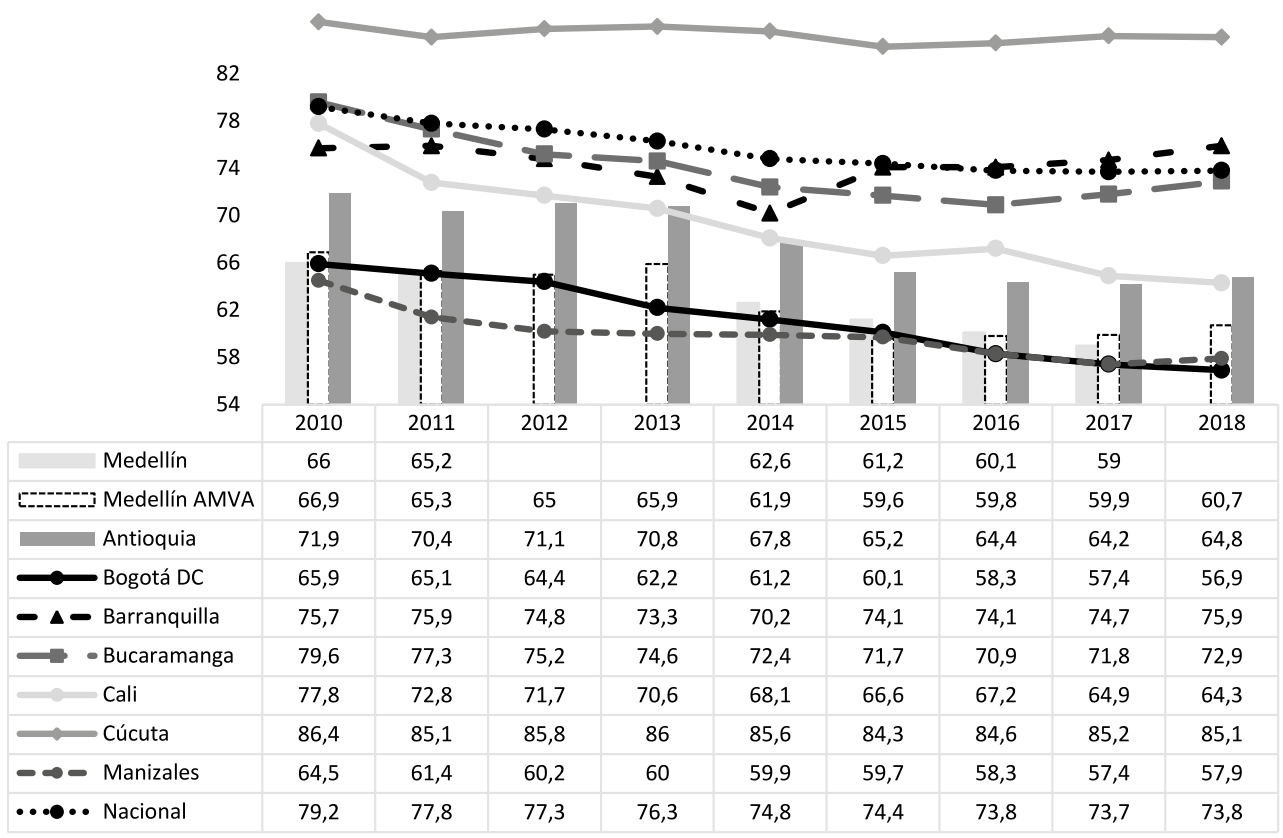

Figura 25. Tasa de trabajo precario para Medellín y otras ciudades: 2010-2018.

Fuente: el autor, con base en GEIH-DANE.

Cúcuta lidera dicha condición con tasas superiores al $80 \%$ entre 2010 y 2018 . La de Medellín viene bajando de manera continua (fenómeno positivo que ocurre en otras ciudades): en 2010 se ubicaba en el 66\% y en 2017 cerró en $59 \%$. Manizales, por su parte, registró la menor tasa promedio (con un $59.9 \%$ ), seguida de Bogotá (con el 61.3\%) (Figura 25). No obstante, este indicador genera alarmas en cuanto a la precariedad del empleo en el país (el porcentaje significativo se debe en su mayoría a la frecuencia de contratos a términos fijos), requiriendo así, el accionar de la administración pública. Claramente, contratos de poca duración, que proliferan cuando hay informalidad, generan incertidumbre al 
trabajador y eso va en contravía de lo que se concibe por trabajo decente. En este sentido, el Gobierno nacional debe desarrollar políticas que generen un buen clima económico, que posibiliten la proliferación de contratos laborales más duraderos $\mathrm{y}$, además, a través del Ministerio del Trabajo, debería realizar con sus inspectores laborales rastreos más estrictos a la calidad de los empleos.

\section{Indicador 6.2 Antigüedad en el trabajo}

Entendida como el promedio de la duración del empleo. La antigüedad en el trabajo persistentemente ha sido superior en Barranquilla (en promedio 86 meses), siguiéndole Manizales con 77,6 y Medellín con 76,9 (cuando se incluye el AMVA, baja a 70,1), lo que indica, por tanto, mayor estabilidad laboral. En el ámbito nacional, la duración media ha sido de 78,9 meses, y en el 2018 está se ubicó en 82,3 , registrando una tendencia alcista desde el 2015, fenómeno igualmente presente en varias ciudades (Figura 26). Aunque no se muestra, al discriminar por perfil ocupacional, los mayores tiempos de antigüedad se lo han llevado históricamente los obreros/ empleados del Gobierno, seguidos de los patrones/empleadores. En último lugar, los obreros/empleados de empresa particular y los trabajadores familiares sin remuneración. En este sentido, una economía con trabajos decentes posibilita el predominio de contratos de larga duración y mayor estabilidad.

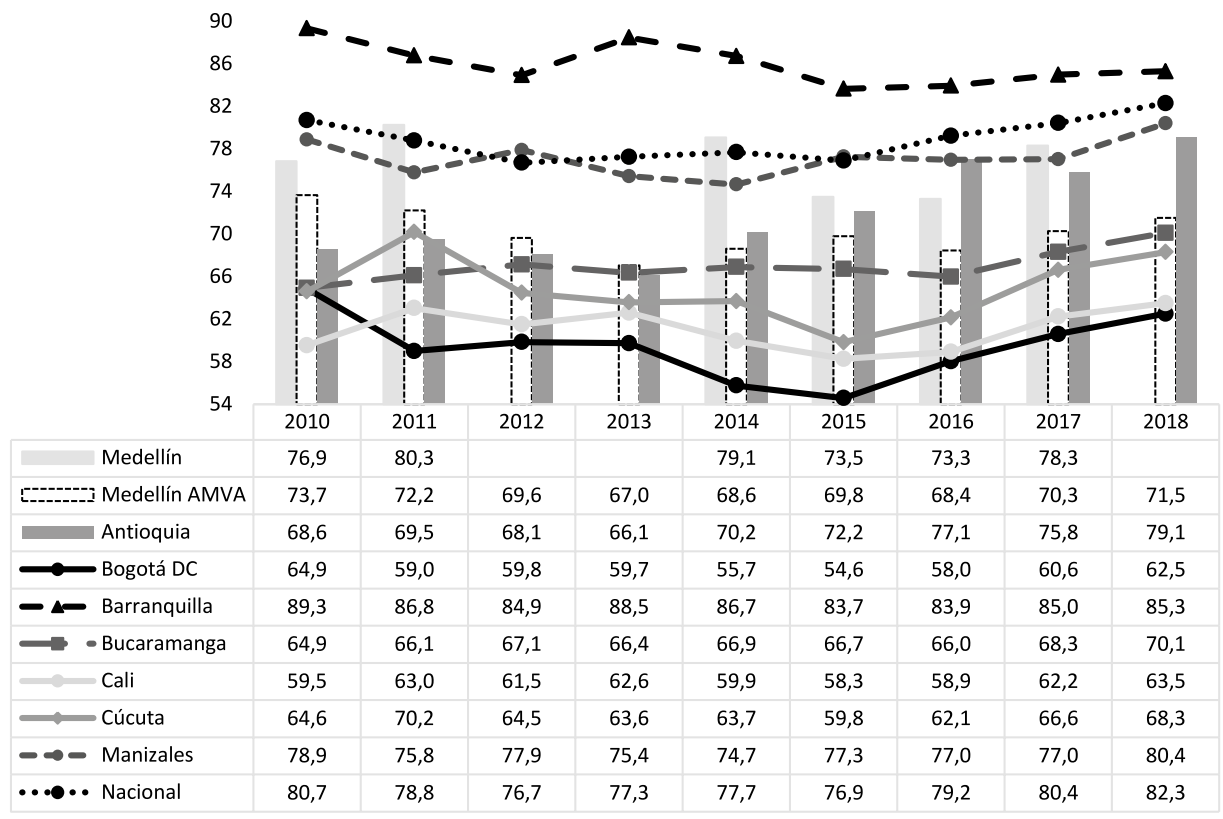

Figura 26. Antigüedad en el trabajo para Medellín y otras ciudades: 2010-2018.

Fuente: el autor, con base en GEIH-DANE. 
Dimensión 7: igualdad de oportunidades y trato en el trabajo

El concepto de trabajo decente recoge igualdad de oportunidades y de trato. A la falta de información de algunas características sociodemográficas de los trabajadores ${ }^{17}$, los dos indicadores relacionados con brechas salariales y condiciones laborales y reportados en esta dimensión muestran la discriminación por género.

\section{Indicador 7.1 Índice de Duncan (se- gregación ocupacional por sexo)}

El índice de Duncan ${ }^{18}$ (1955), permite conocer la discriminación/segregación entre grupos poblacionales. Fue adoptado en economía laboral, en la medida en que se constituye como una expresión de la tradicional división sexual del trabajo, que subvalora aquellas actividades de tradición doméstica o que provienen y han sido desarrolladas por el trabajo no remunerado de la mujer.

Hay segregación ocupacional cuando se asigna determinado tipo de ocupaciones a ciertos perfiles poblacionales sin que esté definido por la naturaleza y aptitudes propias de la ocupación. Esta segregación puede ser de dos clases: la vertical, en la que se observa la distribución de hombres y mujeres a través de distintas posiciones ocupacionales; la horizontal, en que se visualiza la distribución de hombres y mujeres dentro de una misma posición ocupacional para distintos sectores o ramas de actividad económica (Cárdenas, Correa \& Prado, 2014). En este orden de ideas, la no discriminación laboral por género debe ser incluida dentro de la política pública y estar apoyada por el cumplimiento de las normas laborales y de no discriminación.

Son Bogotá, Medellín y Medellín AMVA las que reportan una menor segregación ocupacional promedio entre hombres y mujeres (47, 47,7 y 48,1 respectivamente). En contraste, Barranquilla y Antioquia (con 52,6 y 55,4 respectivamente). Es de destacar también la tendencia bajista en el país $\mathrm{y}$ en varios territorios. No obstante, se evidencia en el país una importante discriminación en contra de la mujer, pues el valor mínimo es de 45,2 (Bogotá en 2018). Y en una economía con trabajo decente registra niveles mínimos de discriminación (Figura 27).

17 Como religión, etnia, discapacidad, orientación sexual, lugar de origen, etc.

18 El índice consiste en la sumatoria de las diferencias de participación porcentual de mujeres y hombres en cada ocupación. Varía entre 0 y 1 , valores que corresponden respectivamente a una distribución exactamente igualitaria y una de máxima segregación. También es expresable en porcentaje, como es el caso. 


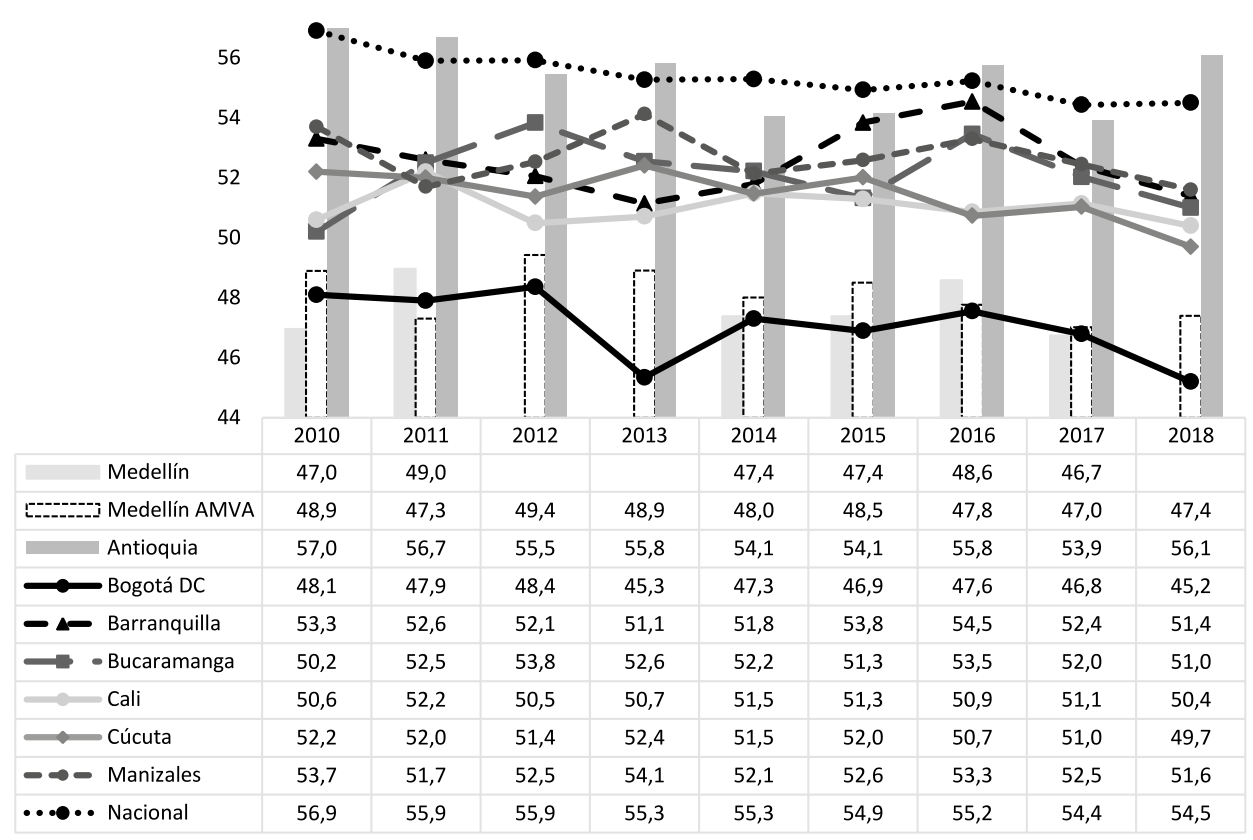

Figura 27. Segregación ocupacional por sexo para Medellín y otras ciudades: 2010-2018.

Fuente: el autor, con base en GEIH-DANE.

Indicador 7.2 Brecha salarial por género

Este indicador mide la diferencia entre los salarios de los hombres y las mujeres, expresado como un porcentaje del salario masculino. Su comportamiento deseable es acercarse a cero, pues indicaría que no existe diferencia entre el salario de los hombres frente al de las mujeres. Las diferencias son importantes a favor de los hombres (el promedio nacional por ejemplo es de 0,95 ), por lo que entonces las mujeres son quienes obtienen menores ingresos a lo largo de su vida, lo que conduce a pensiones más bajas y a un mayor riesgo de estar en la pobreza en la vejez. La situación es más crítica en Antioquia y Cúcuta (con promedios de 0,96 y 0,92 respectivamente) y menos crítica en Bogotá (con 0,87). Una economía con trabajos decentes tiende a reducir la desigualdad laboral por género (Figura 28). 


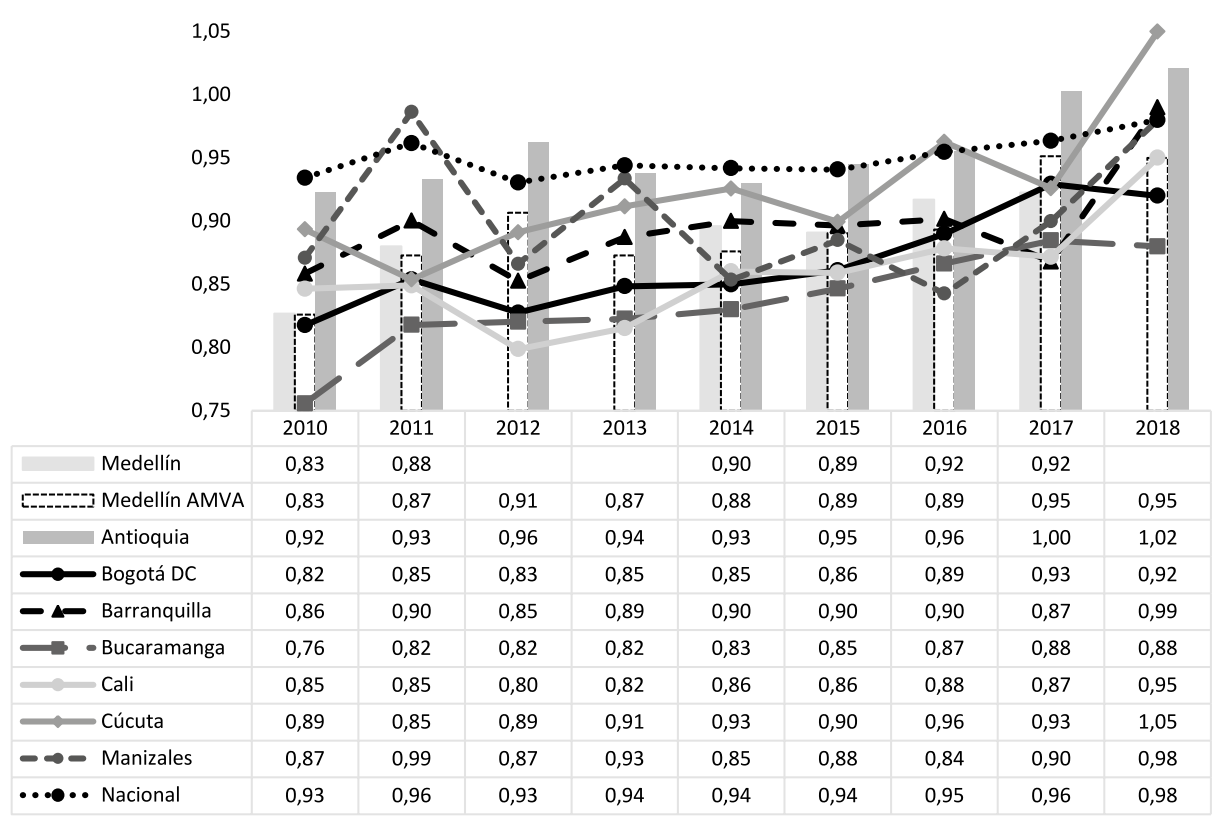

Figura 28. Brecha salarial por género para Medellín y otras ciudades: 2010-2018.

Fuente: el autor, con base en GEIH-DANE.

\section{Dimensión 8: entorno de trabajo seguro}

Aquí se analiza qué tan seguros son los entornos de los trabajos empleando indicadores de accidentes, enfermedades y muertes en el trabajo, a través de dos indicadores. Vale mencionar que en el mundo cada 15 segundos un trabajador muere a causa de accidentes o enfermedades relacionadas con el trabajo, cada 15 segundos 153 trabajadores sufren un accidente laboral y cada día mueren más de seis mil personas a causa de su trabajo $(\mathrm{OIT})^{19}$.
Indicador 8.1 Accidentes, enfermedades y muertes laborales

En términos generales, en el país entre 6 y 8 de cada 100 ocupados sufren algún accidente en su trabajo y en la mayoría de las ciudades se viene presentando una tendencia a la baja; mientras que la mortalidad no supera el $1 \%$. En cuanto a enfermedades laborales, Manizales y Medellín son las ciudades con menor ocurrencia (inferior al $0.08 \%$ ), a diferencia de Cúcuta, Cali y Bogotá (con tasas de hasta el $0.14 \%$ ). A pesar de ello, no se evidencia alguna tendencia preocupante, aunque sí vale mencionar que entre los sectores más afectados

19 https://www.ilo.org/global/topics/safety-and-health-at-work/lang--es/index.htm. 
por el entorno inseguro de los trabajos es el de minas y canteras, siguiéndole construcción. Por ende, es importante que Mintrabajo implemente programas de prevención de accidentes e intervenir aquellos sectores/actividades donde más inseguro es el trabajo (Tabla 2).

Tabla 2. Indicadores de entorno laboral: nacional 2010-2018

\begin{tabular}{ccccccccc}
\hline Año & $\begin{array}{c}\mathbf{N}^{\circ} \\
\text { Empresas }\end{array}$ & $\begin{array}{c}\mathbf{N} .^{\circ} \\
\text { Trabajadores }\end{array}$ & $\begin{array}{c}\mathbf{N} .^{\circ} \\
\text { Accidentes }\end{array}$ & $\begin{array}{c}\mathbf{N}^{\circ} \\
\text { Enfermedades } \\
\text { laborales }\end{array}$ & $\begin{array}{c}\mathbf{N} .^{\circ} \\
\text { Muertes }\end{array}$ & $\begin{array}{c}\text { Promedio de } \\
\text { empleados } \\
\text { por empresa }\end{array}$ & $\begin{array}{c}\text { Tasa de } \\
\text { accidentes } \\
(\%)\end{array}$ & $\begin{array}{c}\text { Tasa de } \\
\text { enfermedad } \\
(\%)\end{array}$ \\
\hline 2010 & 438.083 & 6.813 .664 & 450.564 & 8.902 & 691 & 16 & 6,61 & 0,13 \\
\hline 2011 & 491.056 & 7.499 .489 & 555.479 & 8.277 & 693 & 15 & 7,4 & 0,11 \\
\hline 2012 & 557.377 & 8.430 .802 & 659.170 & 10.053 & 678 & 15 & 7,8 & 0,12 \\
\hline 2013 & 607.957 & 8.271 .920 & 622.486 & 9.483 & 708 & 14 & 7,5 & 0,11 \\
\hline 2014 & 595.066 & 8.936 .937 & 688.942 & 9.710 & 569 & 15 & 7,7 & 0,11 \\
\hline 2015 & 644.011 & 9.656 .829 & 723.696 & 9.583 & 566 & 15 & 7,5 & 0,1 \\
\hline 2016 & 688.107 & 10.039 .533 & 701.696 & 10.572 & 607 & 15 & 6,99 & 0,11 \\
\hline 2017 & 743.449 & 10.237 .811 & 660.110 & 9.692 & 568 & 14 & 6,45 & 0,09 \\
\hline 2018 & 805.737 & 10.487 .600 & 645.119 & 10.450 & 573 & 13 & 6,15 & 0,1 \\
\hline
\end{tabular}

Fuente: tomado de RLDatos, Fasecolda.

\section{Indicador 8.2 Tasa de inspección laboral}

La inspección del trabajo: i) asegura el cumplimiento de las disposiciones legales relativas a las condiciones de trabajo y a la protección de los trabajadores; ii) suministra información técnica y asesora a los empleadores y trabajadores sobre la manera más efectiva de cumplir las disposiciones legales; y (iii) notifica a la autoridad las deficiencias/abusos que no estén cubiertos por la ley (OIT, 2012). Infortunadamente, en el país:

Las inspecciones de trabajo se dedican a atender unas pocas denuncias, hacen una labor mecánica, llenan formatos y no resuelven nada; se apoyan más en los estudiantes de los consultorios jurídicos. [...] la inspección es inocua, porque los inspectores se amparan en la restricción legal, conforme a la cual no pueden declarar derechos, para evadir el control en el cumplimiento de las obligaciones de los empleadores. (Rojas, 2008, p. 1)

La información disponible (ver Tabla 3) evidencia que la inspección laboral es un desafío, al menos en Antioquia, por lo que fortalecer este sistema podría contribuir a reducir la frecuencia de entornos inseguros alrededor del trabajo. En este sentido, se trata no solo de aumentar el número de inspectores de trabajo, sino también de mejorar la calidad de la inspección y fortalecer el sistema de manera que permita validar el cumplimiento de la máxima legislación laboral en el país. 


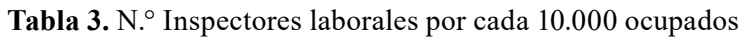

\begin{tabular}{cccc}
\hline Territorio & $\mathbf{2 0 1 2}$ & $\mathbf{2 0 1 3}$ & $\mathbf{2 0 1 4}$ \\
\hline Medellín & $16,2 \%$ & $19,8 \%$ & $21,4 \%$ \\
\hline Antioquia & $15 \%$ & $16 \%$ & $18 \%$ \\
\hline
\end{tabular}

Fuente: elaboración propia, con base en Mintrabajo y GEIH (DANE).

La seguridad y la salud en el trabajo son elementos del trabajo decente, por lo que una política de los gobiernos en sus distintos niveles deberá proteger a los trabajadores de los riesgos y peligros relacionados con el trabajo. Una guía práctica para implementar la inspección laboral en economías altamente informales a través de métodos participativos puede encontrarse en ILO (2017). Adicionalmente, hay que trabajar por una cobertura universal en afiliación a riesgos laborales, acompañada de programas de prevención de accidentes y enfermedades (en conjunto con las aseguradoras) y de un seguimiento a las cifras de enfermedades, accidentes y muertes en el trabajo. Para ello, las estadísticas libres de RLDatos de Fasecolda son de gran utilidad.

\section{Dimensión 9: seguridad social}

Es característico de mercados de trabajo altamente informales como el colombiano, la existencia de empleos que no cuentan con una protección social. Los indicadores que se reportan a continuación evidencian lo anterior.
Indicador 9.1 Participación de beneficiarios de pensión de vejez

Cúcuta es la ciudad con el menor porcentaje de población adulta que recibe pensión de vejez (menos del $20 \%$ ), mientras que Manizales es la de mayor porcentaje (cerca del $40 \%$ ). Se destaca también Medellín, que en 2017 registró un $42.1 \%$, y Medellín AMVA con el $40.9 \%$ (Figura 29). En el ámbito nacional, en promedio, 25 de cada 100 adultos mayores cuentan con pensión. Estos resultados indican entonces que es muy poca la población que recibe pensión en la vejez, situación que afecta la equidad $\mathrm{y}$ el bienestar de sus hogares y, por tanto, impide reconocerle a Colombia la cualidad de trabajo decente.

\section{Indicador 9.2 Porcentaje de la PEA que cotiza en pensión}

En 2017 y 2018, el 33.5\% de la fuerza laboral del país cotizó en un fondo obligatorio de pensiones (el promedio nacional es de $30.5 \%$ ). Cúcuta es nuevamente la capital de las analizadas que más se aleja de la concepción de trabajo decente: en 2018 solo el 24\% de la PET cotiza en pensión (el promedio es el más bajo e igual a $21.9 \%$ ), mientras 
que en Medellín y Medellín AMVA el promedio es cercano a $50 \%$, siguiéndole Manizales con el $46.7 \%$ y Bogotá con el $46.6 \%$ (Figura 30). No obstante, estas cifras son desalentadoras cuando se habla de trabajo decente y más cuando es bien sabido que el sistema pensional del país está diseñado exclusivamente para garantizarles derechos a los trabajadores formales (con un contrato laboral).

Según la OIT (2006), la seguridad social cubre todos los beneficios en efectivo y en especie, que dan protección social a los trabajadores ante los riesgos causados por: a) falta de ingresos laborales a causa de enfermedad, invalidez, mater- nidad, accidentes de trabajo, desempleo, vejez o muerte de un familiar; b) falta de acceso o acceso inasequible a la atención médica; c) falta de apoyo familiar y d) pobreza y exclusión social. Por ello, el acceso a una protección social es considerado como un instrumento para la promoción del desarrollo humano y social, promotor de paz y motor de crecimiento equitativo. Solo una de cada cinco personas en el mundo cuenta con protección social adecuada, y más de la mitad no tiene ninguna cobertura (OIT, s.f.a). Estas personas enfrentan peligros en el lugar de trabajo, y tienen pensiones y seguros de salud débiles o inexistentes.

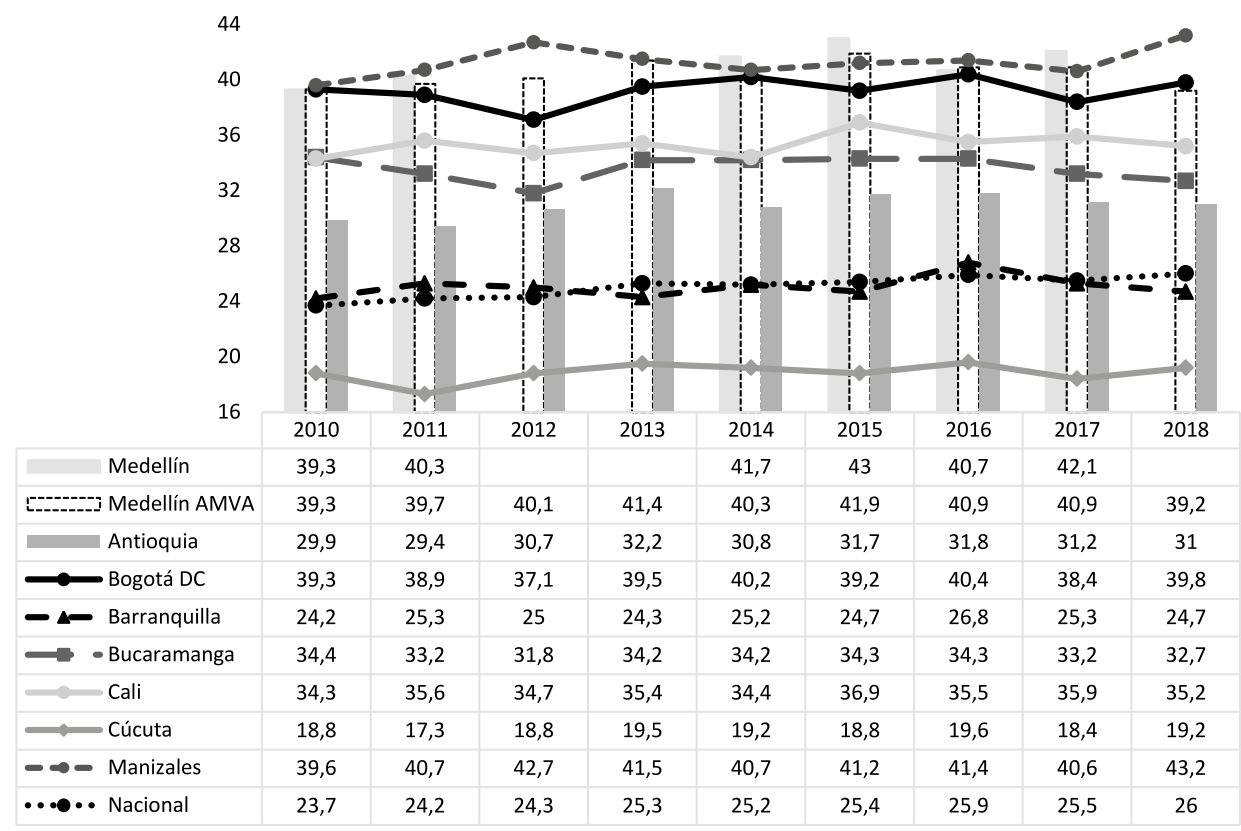

Figura 29. Porcentaje de beneficiarios de pensión para Medellín y otras ciudades: 2010-2018.

Fuente: el autor, con base en GEIH-DANE. 


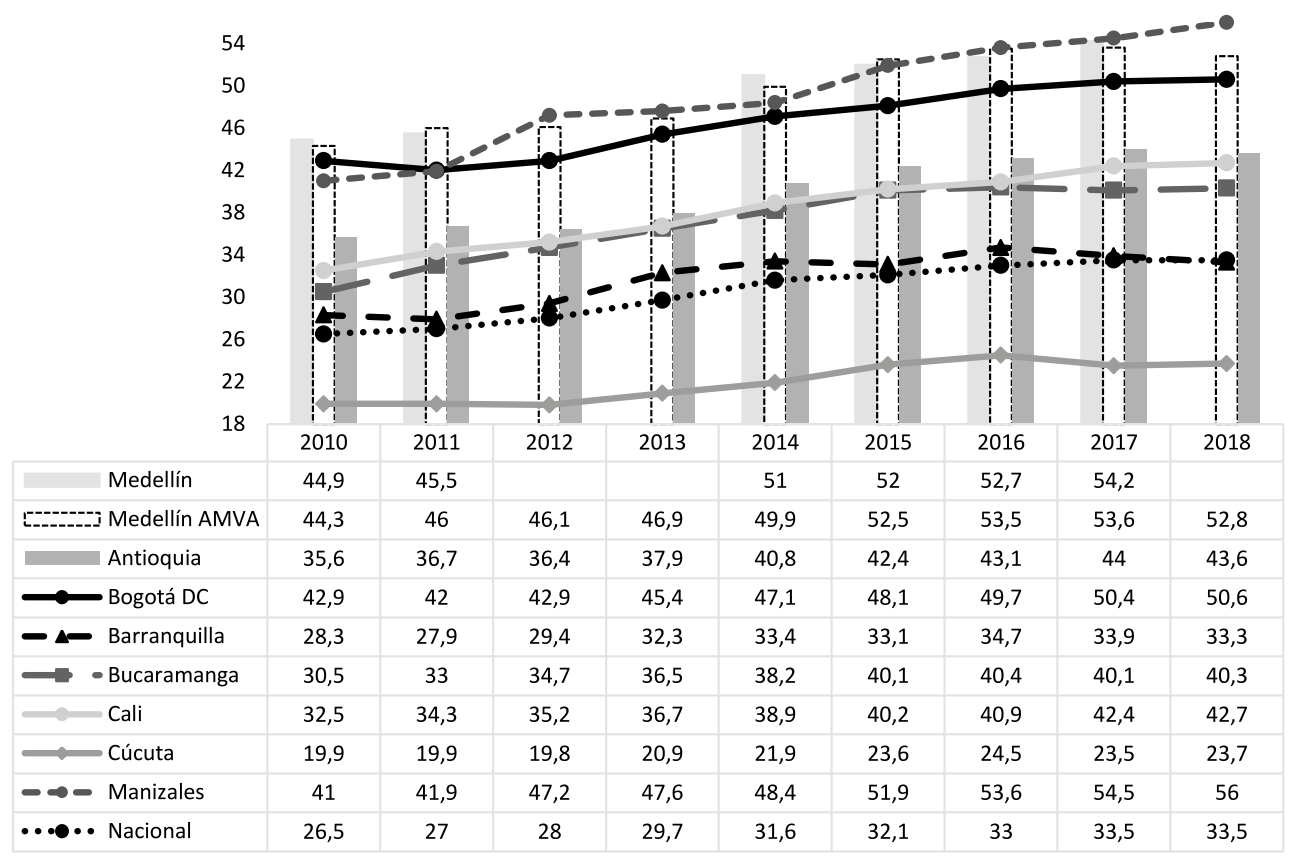

Figura 30. Porcentaje de la PEA que cotiza pensión para Medellín y otras ciudades: 2010-2018.

Fuente: el autor, con base en GEIH-DANE.

Y el país no se aleja de esta realidad. Los indicadores calculados en esta dimensión sustentan el gran interrogante que hay frente a la alta población excluida del sistema de seguridad social y la preocupación por la alta participación de la economía informal. En este sentido, no solo se trata de generar reformas en el sistema pensional o leyes que modifiquen el Código Sustantivo del Trabajo (CST), sino también de propiciar un ambiente económico para que las mipymes, famiempresas y medianas empresas, que conforman la mayor parte del sector empleador, puedan generar empleo formal.
Dimensión 10: diálogo social, representación de los trabajadores y empleadores

El diálogo social es elemento promotor del trabajo decente, pues cuando lo hay es posible resolver o mitigar impactos económicos y sociales, promover el buen gobierno, mejorar la paz y la estabilidad laboral e impulsar el progreso económico (OIT, s.f.). La forma más plausible de medir esta dimensión en el país es analizando la situación de sindicalización y la negociación colectiva. 
Indicador 10.1 Tasa de sindicalización

De acuerdo con cifras de la ENS, para el 2017 existían en el país 5523 sindicatos (en 2016 eran 5449), de los cuales algo más del $70 \%$ son de naturaleza privada. Bogotá aporta con el $25 \%$, le sigue el Valle del Cauca con el $9.3 \%$, Atlántico con el $9.1 \%$ y Antioquia con el $7.4 \%$. En total había más del millón de afiliados, siendo Bogotá la más importante con el $34.4 \%$ de los afiliados, seguida de Antioquia (11.9\%). Estas cifras sugieren que en Colombia el sindicalismo es prácticamente marginal en las relaciones laborales (el $4.6 \%$ para el sector privado y $7 \%$ total), lo que va en contra de lo que se entiende por trabajo decente por la baja representación de los trabajadores, mientras que en países de la OCDE, de la cual Colombia hace parte, la tasa de sindicalización se encuentra entre el 10 y $12 \%$.

\section{Indicador 10.2 Dinámica de la nego- ciación colectiva}

En Colombia, si bien la libertad sindical está amparada por la Constitución en su artículo 39, es sabido que es uno de los países donde resulta más difícil ejercer este derecho (Tabla 4). Mientras que la estabilidad obtenida a través de un proceso de negociación representaba casi un equilibrio que no solo se daba en las fábricas, hoy la estabilidad misma se convierte en una amenaza para muchos y el sentido de riesgo impone nuevas dinámicas de actuación del movimiento sindical (Valencia, 2005). En ese orden de ideas, la sindicalización es un elemento necesario para construir economías con empleos decentes.

Tabla 4. Convenciones, pactos y cobertura de la contratación colectiva: nacional 2006-2016

\begin{tabular}{|c|c|c|c|c|c|c|c|c|}
\hline \multirow{2}{*}{ Nho } & \multicolumn{2}{|c|}{ Comvencibn colectiva } & \multicolumn{2}{|c|}{ Pacto colectivo } & \multicolumn{2}{|c|}{ Centrate sindical } & \multicolumn{2}{|c|}{ Totat } \\
\hline & n' casest & Trab. & Nenes caves & Trab. & No cases & trab. & NE cases & Trab. \\
\hline 2006 & 4.85 & 52.790 & $x$ & 17.632 & 12 & 2.486 & 536 & n.s.ses \\
\hline 2600 & 203 & 62.230 & 206 & 50.000 & 22 & 4.928 & 519 & 127628 \\
\hline 2000 & $2 a 2$ & 60.654 & $2 a 7$ & 04.002 & 40 & 9.065 & 599 & 127396 \\
\hline 2009 & $m$ & $x .13$ & 200 & 47.234 & 46 & 10.306 & 634 & 142.34 \\
\hline 2010 & $2 s 6$ & 62.750 & 225 & 50.624 & so & 11.300 & $\sin$ & 123.674 \\
\hline 2011 & 53 & 93.392 & $2 n 0$ & 32.000 & ist & 37.664 & 687 & 169.676 \\
\hline 2012 & wos & 83.680 & 226 & 48.816 & xos & เ59.782 & 1.253 & 202.236 \\
\hline 2013 & 490 & 75.2211 & 220 & 21.424 & 964 & 42.164 & 1.633 & 145.79 \\
\hline 2614 & $x y$ & 20.89 & 255 & coses & 2.066 & 205.366 & 2680 & 264.459 \\
\hline
\end{tabular}


Continuación Tabla 4

\begin{tabular}{|c|c|c|c|c|c|c|c|c|}
\hline 2615 & 500 & tese $\infty$ & 225 & 304.597 & 1.955 & 1000325 & 2.700 & $313 \times 25$ \\
\hline 2616 & $\Leftrightarrow y$ & 63.559 & 234 & 7.925 & s.o. & 50 & 611 & 455.009 \\
\hline
\end{tabular}

Fuente: tomado de Sislab, ENS.

Partiendo de la información del Sislab (ENS), en 2016 se presentaron 611 casos de negociación colectiva en el país, lo que evidencia una notable caída desde el 2011, además de apoyar la conclusión anterior: en materia de diálogo social, Colombia está lejana de ello y es una de las dimensiones donde más debe poner atención el Gobierno.

El diálogo social juega un rol fundamental para la generación de puestos de trabajo para hombres y mujeres (y el resto de los perfiles poblacionales) en un marco de trabajo decente. La definición de diálogo social incluye todos los tipos de negociación, consulta e intercambio de información entre representantes de gobiernos, empleadores y trabajadores sobre temas de interés común. Las condiciones de empleo justas, el trabajo decente y un desarrollo que beneficie a todos, no pueden ser alcanzados sin el consentimiento y el esfuerzo de trabajadores, empleadores y Gobierno. Por ello, se hace un llamado a esta triada para que se logren acuerdos sociales beneficiosos para la economía que permitan encaminar las condiciones del empleo hacia el trabajo decente.

\section{CONCLUSIONES}

Este estudio da cuenta de que el trabajo decente va más allá de lo que tradicionalmente se ha concebido el mercado laboral en términos de cantidad y calidad, y que el uso de un solo indicador (índice) para diagnosticar la "decencia" del empleo sería erróneo, pues el trabajo decente es un concepto multidimensional, como lo es la pobreza.

A la luz de los principales hallazgos de este estudio, se concluye la pérdida de camino recorrido por el país en materia de ocupación, por el comportamiento no deseable en los últimos años de los indicadores convencionales que cuantifican la problemática del factor cantidad del mundo laboral. Se dejó de reducir el desempleo y la informalidad. En el resto de dimensiones, la nación también registra desafíos importantes, que sin la estimación de los indicadores expuestos aquí no se identificarían en materia de trabajo decente. Aquí es importante entender que una mejora en la tasa de ocupación o de desempleo no significa necesariamente mejoras en términos de trabajo decente, pues como se puede entender de esta concepción del empleo, trabajo decente es más que cantidad y calidad del empleo, aunque sí es cierto que para que exista trabajo 
decente se requiere a lo menos, vacantes suficientes.

Otra conclusión importante es la existencia de larga data de considerables diferencias especiales en el país en materia de trabajo decente. Estas conclusiones confirman entonces que las problemáticas del empleo no se solucionan solo con políticas (activas o pasivas) de empleo, sino que deben ser complementadas con políticas sectoriales y estructurales, y con el diseño e implementación de planes locales y regionales de empleo que focalicen problemáticas específicas ante las brechas existentes entre territorios del país. De las ciudades analizadas, Cúcuta es la que está más distante del trabajo decente.

A manera de síntesis, se podrían definir los siguientes retos de país por cada uno de los cuatro pilares descritos en la sección 1 en el marco del trabajo decente, retos que no solo le competen al Gobierno en sus distintos niveles, sino también a los otros sectores de la triada, pues el diálogo social "merece especial atención ya que a través de este es posible transformar las condiciones económicas, sociales y laborales" (ORMET, 2015, p. 17) del país y sus territorios, a través de un diálogo continuo de los actores.

En cuanto a oportunidades de empleo:

- Acceso a empleos en condiciones de libertad.

- No discriminación.
- Remuneración justa.

- Satisfacer necesidades básicas de los trabajadores.

En cuanto a protección social:

- Acceso a sistemas de seguridad social (salud, pensiones, riesgos laborales, seguro de desempleo).

- Protección y bienestar para el trabajador y su familia.

En cuanto a derechos en el trabajo:

- Respeto y cumplimiento de la legislación laboral nacional e internacional.

- Erradicación de la discriminación laboral y el trabajo infantil.

\section{En cuanto al diálogo social:}

- Derecho a la expresión de opinión y a la defensa de los propios intereses

- Negociación sobre las condiciones del empleo.

- Negociación sobre la política laboral

- Promoción de concertaciones y acuerdos.

Además, es importante hacer seguimiento y evaluación de los programas y las políticas que se implementen en la materia, para identificar aspectos por mejorar y definir las estrategias que están dando buenos resultados y que, por lo tanto, deberían permanecer en el tiempo y replicarse en otros territorios, y cuáles no, así como las políticas más costosoefectivas. 


\section{REFERENCIAS}

Campos, L. (2018, 14 feb.). Asíse vive en la frontera, el eje de la dramática avalancha de venezolanos a Colombia. Revista Semana. Recuperado de: https://www. semana.com/nacion/articulo/crisis-de-migrantes-venezolanos-en-cucuta-colombia/556992

Cárdenas, A., Correa, N. \& Prado, X. (2004). Segregación laboral y género: tendencias y desafíos relativos al mercado laboral de la salud y la educación en Chile. Revista Latinoamericana, 13(38), 397-418. https://doi.org/10.4067/ S0718-65682014000200018

DANE. (2016, abril). Ficha metodológica Gran Encuesta Integrada de Hogares GEIH. Bogotá: Dirección de Metodología y Producción Estadística. Recuperado de: http://www.dane.gov.co/files/investigaciones/fichas/empleo/ficha_metodologica_GEIH-01_V10.pdf.

DANE. (2016a). Metodología general Gran Encuesta Integrada de Hogares GEIH. Bogotá: Dirección de Metodología y Producción Estadística. Recuperado de: http://www.dane.gov.co/files/investigaciones/fichas/metodologia_GEIH01_V9_2.pdf.

Departamento Nacional de Planeación -DNP- (2019). Plan Nacional de Desarrollo 2018-2022. Pacto por Colombia, Pacto por la equidad. Recuperado de: https:// colaboracion.dnp.gov.co/CDT/Prensa/Resumen-PND2018-2022-final.pdf

Duncan, O. \& Duncan, B. (1955). A Methodological Analysis of Segregation Indexes. American Sociological Review, 20, 210-217. https://doi.org/10.2307/2088328

Gobernación del Valle del Cauca. (2019). Gobierno del Valle avanza en implantación de la política pública de empleo decente. Recuperado de: https://www. valledelcauca.gov.co/publicaciones/62117/gobierno-del-valle-avanza-en-implantacion--de-la-politica-publica-de-empleo-decente/

ILO. (2012, May). Decent Work Indicators: Concepts and Definitions. ILO Manual. Geneva: ILO.

ILO. (2017). A Guide on Labour Inspection Intervention in the Informal Economy. A Participatory Method. Retrieved from: https://www.ilo.org/wcmsp5/groups/ public/---ed_dialogue/---lab_admin/documents/publication/wcms_626573. pdf. 
Ministerio de Trabajo. (2017). Línea de política pública para la prevención $y$ erradicación del trabajo infantil y protección integral al adolescente trabajador 2017-2017, Recuperado de http://www.mintrabajo.gov.co/documents/20147/58804143/Politica+publica+pdf_version+final_02042018.pdf

OIT. (1999, June). Trabajo decente. Memoria del director general. En Conferencia Internacional del Trabajo, $87^{a}$ reunión, Ginebra, junio.

OIT (2006). Conferencia Internacional del Trabajo, 95. ${ }^{a}$ reunión. Recuperado de: https://www.ilo.org/public/spanish/standards/relm/ilc/ilc95/pdf/rep-iii-1b.pdf

OIT. (2008, sep.). Medición del trabajo decente. En Documento de debate para la Reunión Tripartita de Expertos sobre Medición del Trabajo Decente, Ginebra, septiembre.

OIT. (s.f.a). Hechos concretos sobre la seguridad social. Recuperado de: https:// www.ilo.org/wcmsp5/groups/public/---dgreports/---dcomm/documents/publication/wcms_067592.pdf

OIT. (s.f.b). Diálogo social. En busca de una voz común. Recuperado de: https:// www.ilo.org/public/spanish/dialogue/download/brochures.pdf

Observatorio del Mercado de Trabajo y la Seguridad Social. (2016). El trabajo decente en Colombia. Boletín 15. Bogotá: Universidad Externado de Colombia.

ORMET Antioquia. (2015). Medición y análisis de las condiciones de trabajo decente en Medellín y el Valle de Aburrá. Informe final. Medellín: ORMET.

Pineda, J. (2013). El trabajo decente en Bogotá. Diagnóstico, análisis y perspectivas. Bogotá: Uniandes.

Procuraduría General de la Nación. (2015). Trabajo digno y decente en Colombia. Seguimiento y control preventivo a las políticas públicas. Bogotá: PGN.

República de Colombia. (1951). Código Sustantivo del Trabajo. Bogotá: Imprenta Nacional.

Rojas, J. (2008). ¿Es eficaz el sistema de inspección de trabajo en Colombia? Actualidad Laboral, (147), Recuperado de: http://legal.legis.com.co/document/Index?obra=rlaboral\&document=rlaboral_7680752a7f85404ce0430a010151404c

Valencia, N. (2005). La negociación colectiva no es sólo un derecho. Revista Cultura y Trabajo, (63). 


\section{Villamizar, M. E. (2011). Uso del tiempo de mujeres y hombres en Colombia. Mi- diendo la inequidad. Serie Cepal, Mujer y Desarrollo, (107).}

\section{ANEXOS}

Anexo 1. Ficha técnica de indicadores por dimensión

\begin{tabular}{|c|c|c|c|}
\hline $\begin{array}{l}\text { Nombre del } \\
\text { indicador }\end{array}$ & Definición del indicador & Fórmula de cálculo & $\begin{array}{l}\text { Unidad de } \\
\text { medida }\end{array}$ \\
\hline \multicolumn{4}{|c|}{ Oportunidades de empleo } \\
\hline Tasa de ocupación & $\begin{array}{c}\text { Porcentaje de personas consideradas como } \\
\text { ocupadas (PO) según definición del DANE con } \\
\text { respecto a la población de } 10 \text { o más años de edad } \\
\text { en zona rural, más la población de } 12 \text { o más años } \\
\text { en zona urbana }\end{array}$ & $\begin{array}{c}(\mathrm{PO} / \mathrm{PET}) \star 100 \\
(\text { Población ocupada / PET) *100 }\end{array}$ & Tasa \\
\hline Tasa de desempleo & $\begin{array}{l}\text { Porcentaje de personas consideradas como } \\
\text { desempleadas (o que se encuentran buscando } \\
\text { empleo) con respecto a la población que integra la } \\
\text { fuerza laboral (población económicamente activa) }\end{array}$ & $\begin{array}{c}\text { (PD / PEA)*100 } \\
\text { (Población desempleada / Población } \\
\text { económicamente activa) })^{*} 100\end{array}$ & Tasa \\
\hline $\begin{array}{l}\text { Jóvenes que no } \\
\text { están estudiando ni } \\
\text { trabajando }\end{array}$ & $\begin{array}{l}\text { Porcentaje de jóvenes de } 14 \text { a } 28 \text { años que no se } \\
\text { encuentran estudiando ni trabajando con respecto } \\
\text { a la población total joven de } 14 \text { a } 28 \text { años de edad }\end{array}$ & $\begin{array}{c}\text { (NINIS/ J 14-28**100 } \\
\text { Jóvenes de } 14 \text { a } 28 \text { años que no pertenecen } \\
\text { a la población ocupada y no ocuparon la } \\
\text { semana pasada en estudio / Jóvenes de } 14 \\
\text { a } 28 \text { años }\end{array}$ & $\%$ \\
\hline $\begin{array}{l}\text { Tasa de empleo } \\
\text { informal por tamaño } \\
\text { de empresa }\end{array}$ & $\begin{array}{l}\text { Porcentaje de la población ocupada informal con } \\
\text { respecto a la población total ocupada, según } \\
\text { definición tamaño de empresa del DANE }\end{array}$ & $\begin{array}{c}(\text { POIF/PO)*100 } \\
\text { (Población ocupada informal / Población } \\
\text { ocupada) })^{* 100}\end{array}$ & Tasa \\
\hline $\begin{array}{l}\text { Tasa de empleo } \\
\text { informal por afiliación } \\
\text { a SGSSS }\end{array}$ & $\begin{array}{c}\text { Porcentaje de la población ocupada que no está } \\
\text { afiliada al sistema de salud o a pensiones del total } \\
\text { de la población ocupada }\end{array}$ & $\begin{array}{c}\text { (POIF2/PO)*100 } \\
\text { (Población ocupada que no se encuentra } \\
\text { afiliada a salud o a pensiones / Población } \\
\text { ocupada)*100 }\end{array}$ & Tasa \\
\hline $\begin{array}{l}\text { Tasa global de } \\
\text { participación }\end{array}$ & $\begin{array}{l}\text { Porcentaje de la fuerza laboral con respecto a la } \\
\text { población en edad de trabajar. }\end{array}$ & $\begin{array}{c}\text { (PEA / PET) }{ }^{\star} 100 \\
\text { (Población económicamente activa / } \\
\text { Población en edad de trabajar) }{ }^{*} 100\end{array}$ & Tasa \\
\hline $\begin{array}{l}\text { Tasa de desempleo } \\
\text { juvenil }\end{array}$ & $\begin{array}{l}\text { Porcentaje de población de } 14 \text { a } 28 \text { años que se } \\
\text { encuentra desempleada (o buscando empleo) con } \\
\text { respecto a la fuerza laboral de } 14 \text { a } 28 \text { años }\end{array}$ & $\begin{array}{l}\text { (PDJ / PEAJ)*100 } \\
\text { (Población desempleada de } 14 \text { a } 28 \text { años de } \\
\text { edad / Población económicamente activa de } \\
14 \text { a } 28)^{\star} 100\end{array}$ & Tasa \\
\hline $\begin{array}{l}\text { Tasa de desempleo } \\
\text { por nivel educativo }\end{array}$ & $\begin{array}{l}\text { Porcentaje de población que se encuentra en } \\
\text { estado de desempleo por nivel educativo (ninguno, } \\
\text { preescolar, básica primaria, básica secundaria, } \\
\text { media y superior) con respecto al total de la } \\
\text { población económicamente activa }\end{array}$ & $\begin{array}{l}(\mathrm{PD} / \mathrm{PEA})^{\star} 100 \text { por nivel } \\
\text { Población desempleada por nivel educativo / } \\
\text { Población fuerza laboral })^{*} 100\end{array}$ & Tasa \\
\hline $\begin{array}{l}\text { Ocupados según } \\
\text { la situación en la } \\
\text { ocupación }\end{array}$ & $\begin{array}{l}\text { Participación porcentual de los ocupados según su } \\
\text { situación ocupacional en el empleo principal }\end{array}$ & $\begin{array}{l}\text { (PO por posición ocupacional / PO)¹00 } \\
\text { (Población ocupada según su posición } \\
\text { ocupacional / Población ocupada total) }{ }^{\star} 100\end{array}$ & $\%$ \\
\hline $\begin{array}{l}\text { Proporción de } \\
\text { ocupados cuenta } \\
\text { propia y trabajadores } \\
\text { familiares }\end{array}$ & $\begin{array}{l}\text { Proporción de ocupados cuya situación en el } \\
\text { empleo puede exponerlos a un mayor riesgo } \\
\text { económico que las demás personas ocupadas por } \\
\text { ser trabajadores cuenta propia o familiares }\end{array}$ & $\begin{array}{c}\text { (POCP/PO)*100 } \\
\text { (Número total de trabajadores por cuenta } \\
\text { propia y trabajadores familiares / población } \\
\text { ocupada total)*100 }\end{array}$ & $\%$ \\
\hline $\begin{array}{l}\text { Proporción de } \\
\text { asalariados no- } \\
\text { agrícolas respecto al } \\
\text { total de ocupados }\end{array}$ & $\begin{array}{l}\text { Participación del empleo asalariado en la } \\
\text { ocupación no agrícola }\end{array}$ & $\begin{array}{c}\text { (PONA / PO)*100 } \\
\text { (Número de ocupados asalariados en el } \\
\text { sector no agrícola / ocupados totales en el } \\
\text { sector no agrícola)*100 }\end{array}$ & $\%$ \\
\hline
\end{tabular}




\begin{tabular}{|c|c|c|c|}
\hline \multicolumn{4}{|c|}{ Ingresos suficientes y productividad } \\
\hline $\begin{array}{l}\text { Tasa de ocupados } \\
\text { pobres }\end{array}$ & $\begin{array}{l}\text { Porcentaje de la población que, si bien se } \\
\text { encuentra ocupada, vive en la pobreza; esto es, el } \\
\text { ingreso familiar per cápita es inferior a la línea de } \\
\text { pobreza según año y territorio }\end{array}$ & $\begin{array}{c}(\mathrm{POP} / \mathrm{PO})^{\star} 100 \\
\text { (Población ocupada en condiciones de } \\
\text { pobreza monetaria / Población ocupada)*100 }\end{array}$ & Tasa \\
\hline $\begin{array}{l}\text { Tasa de asalariados } \\
\text { con bajos ingresos }\end{array}$ & $\begin{array}{l}\text { Relación porcentual de ocupados asalariados que } \\
\text { trabajan por salarios bajos }\end{array}$ & $\begin{array}{l}\text { (Número de asalariados pagados con menos } \\
\text { de } 2 / 3 \text { de la mediana del salario por hora / } \\
\text { Asalariados totales) }{ }^{*} 100\end{array}$ & $\%$ \\
\hline $\begin{array}{l}\text { Ingresos laborales } \\
\text { medios por hora }\end{array}$ & Ingreso laboral medio por hora & $\begin{array}{c}((\text { Ingreso laboral mensual / Horas trabajadas } \\
\text { a la semana*4)/ PO) }\end{array}$ & Número \\
\hline $\begin{array}{l}\text { Salario promedio } \\
\text { real }\end{array}$ & $\begin{array}{l}\text { Ingreso laboral mensual promedio de asalariados a } \\
\text { precios constantes de } 2008\end{array}$ & $\begin{array}{l}\text { (Ingreso laboral mensual de asalariados / } \\
\text { Promedio IPC mensual según año)*100 }\end{array}$ & Número \\
\hline $\begin{array}{l}\text { Salario mínimo } \\
\text { como porcentaje del } \\
\text { salario mediano }\end{array}$ & $\begin{array}{l}\text { Proporción del salario mediano mensual con } \\
\text { respecto al salario mínimo mensual legal vigente }\end{array}$ & $\begin{array}{l}\text { (Mediana del ingreso laboral mensual de } \\
\text { asalariados / SMMLV según año)*100 }\end{array}$ & $\%$ \\
\hline \multicolumn{4}{|c|}{ Tiempo de trabajo decente } \\
\hline $\begin{array}{l}\text { Tiempo de trabajo } \\
\text { excesivo }\end{array}$ & $\begin{array}{l}\text { Porcentaje de los ocupados que laboran en la } \\
\text { semana más de las } 48 \text { horas legales }\end{array}$ & $\begin{array}{c}(\mathrm{POE} / \mathrm{PO})^{\star} 100 \\
\text { (Población ocupada en jornadas de } \\
\text { más de } 48 \text { horas semanales / Población } \\
\text { ocupada) })^{*} 100\end{array}$ & $\%$ \\
\hline $\begin{array}{l}\text { Ocupados por horas } \\
\text { de trabajo a la } \\
\text { semana }\end{array}$ & $\begin{array}{l}\text { Participación porcentual de los ocupados según } \\
\text { rango de horas trabajadas a la semana }\end{array}$ & $\begin{array}{l}\text { (PO según horas de trabajo / PO)*100 } \\
\text { (Población ocupada según rango de horas de } \\
\text { trabajo a la semana / Población ocupada)*100 }\end{array}$ & $\%$ \\
\hline $\begin{array}{l}\text { Tasa de subempleo } \\
\text { (TS) }\end{array}$ & $\begin{array}{c}\text { Relación porcentual entre el número de personas } \\
\text { subempleadas y el de personas que integran la } \\
\text { fuerza laboral }\end{array}$ & $\begin{array}{c}(\mathrm{S} / \mathrm{PEA})^{*} 100 \\
\text { (Ocupados con característica de } \\
\text { subempleo objetivo o subjetivo / Población } \\
\text { económicamente activa) })^{*} 100\end{array}$ & Tasa \\
\hline $\begin{array}{l}\text { Subempleo objetivo } \\
\text { total }\end{array}$ & $\begin{array}{c}\text { Relación porcentual entre el número de personas } \\
\text { subempleadas y personas que integran la fuerza } \\
\text { laboral }\end{array}$ & $\begin{array}{c}(\mathrm{SO} / \mathrm{PEA})^{\star} 100 \\
\text { Ocupados con al menos una de las } \\
\text { características de subempleo objetivo / PEA }\end{array}$ & Tasa \\
\hline \multicolumn{4}{|c|}{ Conciliación del trabajo, la vida familiar y la vida personal } \\
\hline $\begin{array}{l}\text { Tasa de tiempo } \\
\text { de trabajo no } \\
\text { remunerado frente al } \\
\text { remunerado }\end{array}$ & $\begin{array}{l}\text { Razón del número de horas semanales destinadas } \\
\text { a actividades no remuneradas frente al número de } \\
\text { horas semanales destinadas a trabajo remunerado }\end{array}$ & $\begin{array}{l}\text { Número de horas de trabajo no remunerado } \\
\text { semanales / Número de horas de trabajo } \\
\text { remunerado semanales }\end{array}$ & Razón \\
\hline \multicolumn{4}{|c|}{ Trabajo que debería abolirse } \\
\hline $\begin{array}{l}\text { Tasa de trabajo } \\
\text { infantil }\end{array}$ & $\begin{array}{l}\text { Porcentaje de la población infantil (10-17 años) que } \\
\text { se encuentra ocupada frente a la población total de } \\
\qquad 10-17 \text { años }\end{array}$ & $\begin{array}{c}(\mathrm{POI} / \mathrm{PIN})^{*} 100 \\
\text { (Población de } 10 \text { a } 17 \text { años ocupadas / } \\
\text { Población de } 10 \text { a } 17 \text { años)*100 }\end{array}$ & Tasa \\
\hline \multicolumn{4}{|c|}{ Estabilidad y seguridad del trabajo } \\
\hline $\begin{array}{l}\text { Tasa de empleo } \\
\text { precario }\end{array}$ & $\begin{array}{c}\text { Porcentaje de ocupados con contrato a término } \\
\text { fijo o vinculados a través de empresas de servicios } \\
\text { temporales, cooperativas de trabajo asociado o } \\
\text { empresa asociativa de trabajo con respecto al total } \\
\text { de ocupados }\end{array}$ & $\begin{array}{c}\text { (POPR/POI)*100 } \\
\text { (Población ocupada con contrato a término } \\
\text { fijo o vinculados temporalmente, con } \\
\text { asociativas o cooperativas de trabajo / } \\
\text { Población ocupada) }{ }^{\star} 100\end{array}$ & Tasa \\
\hline
\end{tabular}




\begin{tabular}{|c|c|c|c|}
\hline $\begin{array}{l}\text { Antigüedad en el } \\
\text { trabajo }\end{array}$ & $\begin{array}{c}\text { Antigüedad laboral de los trabajadores en su } \\
\text { trabajo actual o principal o con su empleador } \\
\text { actual. } \\
\text { Promedio de la duración del empleo }\end{array}$ & $\begin{array}{l}\text { (Sumatoria de horas / PO })^{*} 100 \\
\text { Número de meses en total trabajados / } \\
\text { Población ocupada }\end{array}$ & Número \\
\hline \multicolumn{4}{|c|}{ Igualdad de oportunidades y trato en el trabajo } \\
\hline $\begin{array}{l}\text { Segregación } \\
\text { ocupacional por sexo }\end{array}$ & $\begin{array}{c}\text { Indicador de discriminación en la } \\
\text { medida en que es expresión de la tradicional } \\
\text { división sexual del trabajo, que subvalora aquellas } \\
\text { actividades de tradición doméstica o que provienen } \\
\text { y han sido desarrolladas por el trabajo no } \\
\text { remunerado de la mujer }\end{array}$ & $\begin{array}{c}0,5^{*} \text { Sumatoria|Mi/M }-\mathrm{Hi} / \mathrm{H} \mid \text { desde } \mathrm{i}=1 \mathrm{a} \\
82, \text { donde I es el número de ocupaciones } \\
\text { definidas por CIUO-88 }\end{array}$ & Razón \\
\hline $\begin{array}{l}\text { Brecha salarial por } \\
\text { género }\end{array}$ & $\begin{array}{l}\text { Diferencia entre los salarios de los hombres y las } \\
\text { mujeres por concepto de su trabajo, expresado } \\
\text { como un porcentaje de los salarios masculinos }\end{array}$ & $\begin{array}{c}((E m-E w) / E m) \times 100((\text { Salario promedio } \\
\text { por hora de los hombres - Salario promedio } \\
\text { por hora de las mujeres }) / \text { Salario promedio por } \\
\text { hora de hombres })^{*} 100\end{array}$ & Número \\
\hline \multicolumn{4}{|c|}{ Entorno de trabajo seguro } \\
\hline $\begin{array}{l}\text { Índice de frecuencia } \\
\text { de accidentes de } \\
\text { trabajo mortales }\end{array}$ & Número de accidentes mortales & Número de accidentes laborales mortales & Número \\
\hline $\begin{array}{l}\text { Índice de frecuencia } \\
\text { de accidentes de } \\
\text { trabajo no-mortales }\end{array}$ & Número de accidentes no mortales & Número de accidentes laborales no mortales & Número \\
\hline Inspección laboral & $\begin{array}{l}\text { Porcentaje de inspectores por cada diez mil } \\
\text { ocupados }\end{array}$ & $\begin{array}{l}\text { Número de inspectores (MINT) /diez mil } \\
\text { ocupados (GEIH) }\end{array}$ & $\%$ \\
\hline \multicolumn{4}{|c|}{ Seguridad social } \\
\hline $\begin{array}{l}\text { Participación de } \\
\text { los beneficiarios de } \\
\text { pensiones de vejez }\end{array}$ & $\begin{array}{c}\text { Porcentaje de la población adulta que recibe } \\
\text { pensión de vejez }\end{array}$ & $\begin{array}{c}\text { (PAP / PA)*100 } \\
\text { Población mayor de } 65 \text { años o más receptora } \\
\text { de pensión / Población de } 65 \text { años o más }\end{array}$ & $\%$ \\
\hline $\begin{array}{l}\text { Proporción de la } \\
\text { PEA que cotiza a un } \\
\text { fondo de pensión } \\
\text { (obligatorio) }\end{array}$ & $\begin{array}{l}\text { Porcentaje de la fuerza laboral que cotiza en un } \\
\text { fondo obligatorio de pensiones }\end{array}$ & $\begin{array}{c}\text { (POCP/PEA) })^{\star} 100 \\
\text { (Población de la fuerza laboral que cotiza } \\
\text { a un fondo de pensiones / Población } \\
\text { económicamente activa) })^{\star} 100\end{array}$ & $\%$ \\
\hline \multicolumn{4}{|c|}{ Diálogo social, representación de los ocupados y empleadores } \\
\hline $\begin{array}{c}\text { Tasa de } \\
\text { sindicalización }\end{array}$ & $\begin{array}{l}\text { Porcentaje de la población ocupada que es } \\
\text { sindicada }\end{array}$ & $\begin{array}{l}\text { Población ocupada que hace parte de una } \\
\text { asociación gremial-sindical / PO }\end{array}$ & Tasa \\
\hline $\begin{array}{l}\text { Tasa de cobertura } \\
\text { de la negociación } \\
\text { colectiva }\end{array}$ & $\begin{array}{l}\text { Número de convenios firmados como negociación } \\
\text { colectiva }\end{array}$ & Número de convenios firmados & Número \\
\hline
\end{tabular}

Fuente: elaboración del autor. 